\title{
Current and future applications of GnRH, kisspeptin and neurokinin B analogues
}

\author{
Robert P Millar ${ }^{1,2,3}$, Claire Newton ${ }^{2}$ \\ 1. The Mammal Research Institute, Department of Zoology and Entomology, University of Pretoria, Pretoria, South Africa \\ 2. UCT/MRC Receptor Biology Research Unit, Institute of Infectious Diseases and Molecular Medicine, University of Cape \\ Town, Cape Town, South Africa \\ 3. Centre of Integrative Physiology, University of Edinburgh, Edinburgh, UK
}

\begin{abstract}
Reproductive hormones impact on all stages of life from gamete production, fertilisation, fetal development and parturition, neonatal development and puberty through to adulthood and senescence. The reproductive hormone cascade has therefore been the target for the development of numerous drugs which modulate its activity at many levels. As the central regulator of the cascade, gonadotropinreleasing hormone $(\mathrm{GnRH})$ agonists and antagonists have found extensive applications in treating a wide range of hormone-dependent deseases such as precocious puberty, prostate cancer, benign prostatic hyperplasia, endometriosis and uterine fibroids, as well as being an essential component of in vitro fertilisation (IVF) protocols. Recently-discovered neuroendocrine peptides, kisspeptin (KP) and neurokinin $B(\mathrm{NKB})$, have also been identified as therapeutic targets and novel agonists and antagonists are being developed as modulators of the cascade upstream of $\mathrm{GnRH}$. Here we review the development and applications of analogues of the major neuroendocrine peptide regulators of the reproductive hormone cascade, $\mathrm{GnRH}, \mathrm{KP}$ and $\mathrm{NKB}$.
\end{abstract}

\section{Introduction}

The development of synthetic molecules that modulate reproductive hormones has had a major impact on our lives. Arguably, the development of the contraceptive pill for woman was the singular most important contribution to women's liberation and increased participation in professional and public life. On the other hand, anabolic steroids are the most utilised enhancer of competitive athletic performance, while estrogen and androgen antagonists, and inhibitors of their synthesis and bioconversion, are 
extensively employed as therapeutics for breast and prostatic cancers; two of the prevalent cancers in men and women.

In addition to breast and prostatic cancers, a wide range of tissues are stimulated by sex steroid hormones and a large array of hormone-dependent diseases arise from dysfunctional sex hormone stimulation. These include benign prostatic hyperplasia, bone loss, endometriosis, polycystic ovarian syndrome (PCOS), uterine fibroids, ovarian cancer, muscle wasting, various aspects of metabolism and cognitive function (Table1).

Table 1.

\section{Current and potential applications of HPG axis analogues}

\section{A. Gonadal Function}

Female and male contraception

Female and male infertility induction of ovulation/IVF

Delayed puberty

Precocious puberty

Hypothalamic amenorrhoea

B. Sex steroid-dependent reproductive diseases

Male

Prostate cancer

Benign prostatic hyperplasia

Female

Endometriosis

Uterine fibroids

Polycystic ovarian syndrome

Breast cancer

Ovarian cancer

\section{Muscle and bone}

Bone loss (osteoporosis)

Muscle loss in ageing and catabolic states

D. Brain

Cognitive function

Senile dementia and Alzheimer's disease

E. Metabolism

Obesity

Hypogonadism in diabetes

Reduced lean body mass in ageing

Regulation of the reproductive system is initiated by an array of external and internal inputs such as photoperiod, metabolic products and nutrients, growth factors, stress, infection and inflammation, as well as many central and peripheral growth factors and hormones. These inputs are integrated in the brain and hypothalamus to regulate the biosynthesis and secretion of gonadotropin-releasing-hormone 

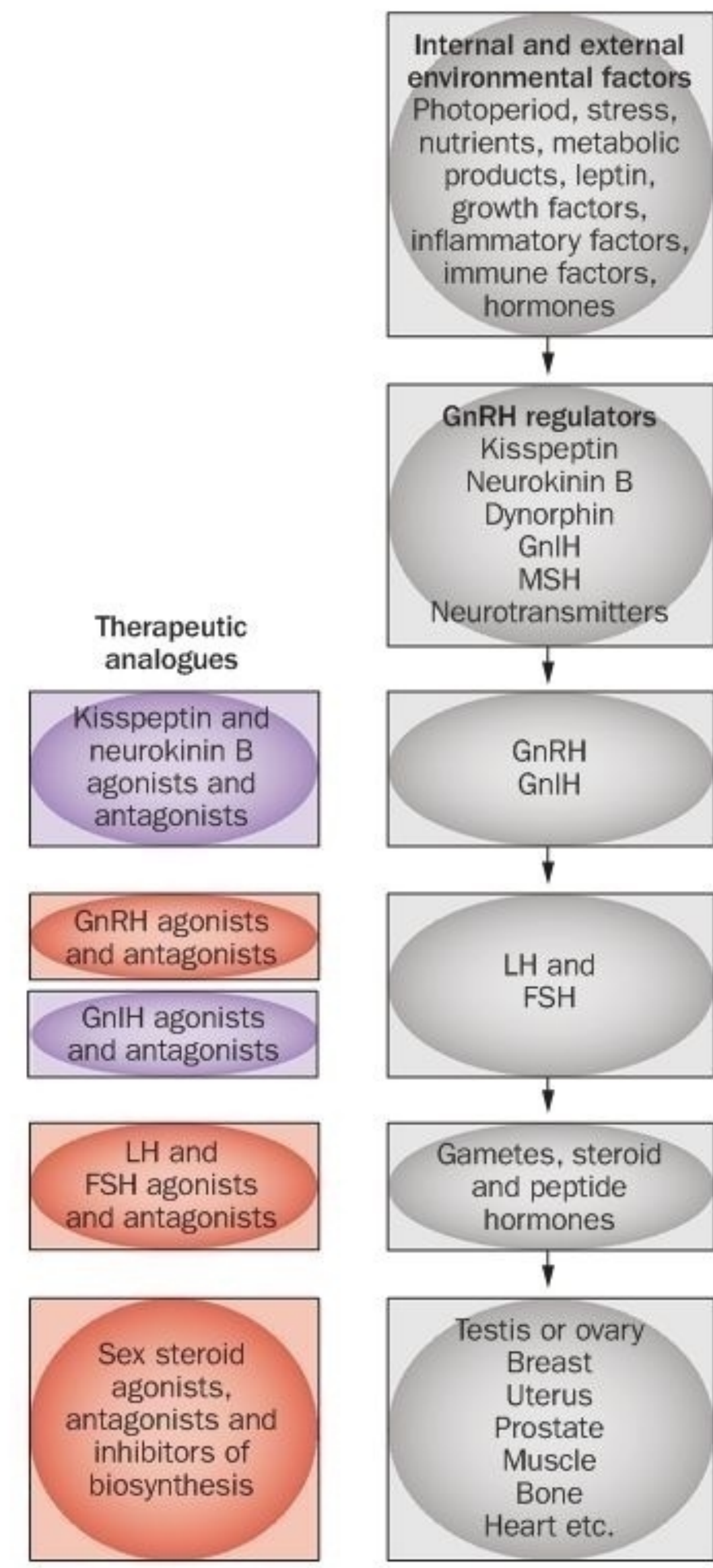

Therapeutic analogues

isspeptin and neurokinin B agonists and antagonists
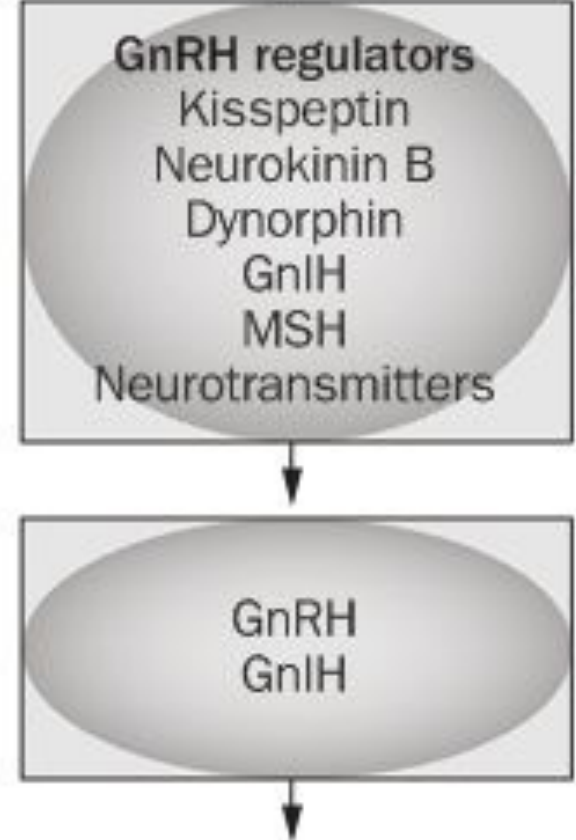

Hypothalamus

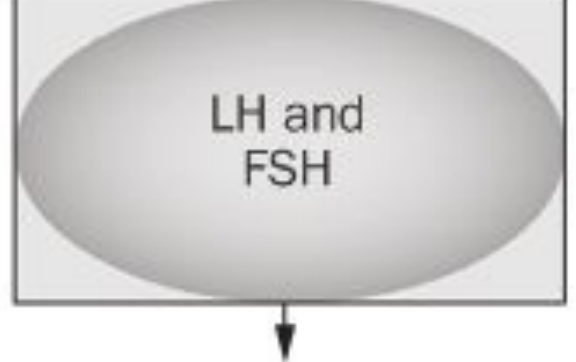

Hypothalamus

Gonadal steroid and peptide hormone positive and negative feedback

Figure 1 | The reproductive hormone cascade and therapeutic analogues that target the cascade. The figure shows the diverse internal and external factors regulating brain neuroendocrine neuropeptides, which in turn regulate downstream $\mathrm{GnRH}$, pituitary gonadotropins and gonadal hormones. Positive and negative feedback by gonadal steroids and peptides is also shown. Analogues have been developed that target all levels of the cascade. Those in clinical use are highlighted in red boxes, those in purple boxes are being developed but are not yet in clinical use. Abbreviations: FSH, follicle-stimulating hormone; $\mathrm{GnRH}$, gonadotropinreleasing hormone; GnlH, gonadotropin-inhibitory hormone; LH, luteinizing hormone; MSH, melanocyte-stimulating hormone. 
$(\mathrm{GnRH})$ (Figure 1). $\mathrm{GnRH}$ is conducted by portal vessels to the anterior pituitary where it engages the gonadotrope $\mathrm{GnRH}$ receptor ( $\mathrm{GnRHR}$ ) to recruit intracellular signalling machinery which stimulates the biosynthesis and secretion of the gonadotropins, luteinizing hormone (LH) and follicle stimulating hormone $(\mathrm{FSH})^{1,2}$. $\mathrm{LH}$ and $\mathrm{FSH}$ then act on the ovary and testis to stimulate the production of gametes and steroid and peptide hormones. These hormones feedback in positive and negative modalities at the hypothalamus and pituitary to regulate the reproductive hormone cascade ${ }^{1,3}$.

The diverse external and internal factors regulating $\mathrm{GnRH}$ do so through a complex network of neurotransmitters and neuropeptides in the central nervous system (CNS) and hypothalamus ${ }^{3-5}$. Inactivating mutations of two of these, kisspeptin (KP) and neurokinin $B(N K B)$, or their cognate receptors, recently highlighted the crucial role of these neuropeptides in $\mathrm{GnRH}$ neurone activation, as these mutations result in a failure to progress through puberty and in adult infertility ${ }^{6-11}$. In addition to these major modulators of $\mathrm{GnRH}$ secretion, neuropeptide $\mathrm{Y}$, products of the pro-opiomelanocortin protein, gonadotropin-inhibitory-hormone $(\mathrm{GnIH})$ and neurotransmitters such as gamma amino butyric acid and glutamine also regulate $\mathrm{GnRH}$ neurone activity ${ }^{12,13}$.

All of the hormones in the cascade from the brain to the pituitary, gonads and peripheral tissues are potential targets for the development of analogues which modulate the production of gametes, and sex steroid hormones which impact on diverse target tissues. The sites of current and potential intervention in the reproductive hormone cascade are indicated in Figure 1.

Sex steroid agonists, antagonists and inhibitors of their synthesis have been extensively employed for contraception and hormone-dependent diseases over many years. GnRH and its analogues have likewise received wide application in hormone-dependent diseases. Natural and recombinant gonadotropins are the mainstay of the treatment of delayed puberty, infertility and assisted reproductive technologies such as in vitro fertilisation (IVF) in which they are used along with GnRH analogues which suppress endogenous gonadotropin. Although the novel neuropeptides, KP, NKB and gonadotropininhibitory-hormone (GnlH / RFRP3), which regulate $\mathrm{GnRH}$ neurones, are cogent targets for regulation of the reproductive system, the use of agonist and antagonist analogues has been restricted to animal 
studies and have yet to be developed as regulators of the reproductive system in humans. NKB and GnlH analogues have been studied in humans but with a focus on therapeutic applications in CNS conditions such as pain and schizophrenia. Thus, these analogues have already met regulatory requirements for use in humans and are available to 'fast track' clinical research into the role of these neuropeptides in the reproductive system.

As a review on all the hormone analogues in the entire reproductive hormone cascade (Figure 1) would be excessively vast, we restrict the current review to analogues of the neuroendocrine peptides, GnRH, KP and NKB.

Only brief background to the discovery and physiology of the peptides is given as reference is made to existing comprehensive reviews.

\section{GnRH Analogues}

\section{Background}

$\mathrm{GnRH}$, the central initiator of the reproductive hormonal cascade, was first isolated from mammalian hypothalami as the decapeptide, pGlu-His-Trp-Ser-Tyr-Gly-Leu-Arg-Pro-Gly- $\mathrm{NH}_{2}{ }^{14-16}$. GnRH is synthesised in approximately 1000 specialised neurones of the hypothalamus from a precursor polypeptide by enzymatic processing and packaged in storage granules that are transported down axons to the external zone of the median eminence ${ }^{1,2}$. GnRH is released in synchronised pulses from the GnRH nerve endings into the hypophyseal portal system every 30-120 min to stimulate the biosynthesis and secretion of $\mathrm{LH}$ and FSH from pituitary gonadotropes ${ }^{1}$. Each $\mathrm{GnRH}$ pulse stimulates a pulse of $\mathrm{LH}$. However, FSH pulses are less clear due to its longer half-life. The frequency of pulses is highest at the $\mathrm{LH}$ surge of ovulation and lowest during the luteal phase of the ovarian cycle. The asynchronous patterns of $\mathrm{LH}$ and FSH release result from changes in $\mathrm{GnRH}$ pulse frequency, the modulating effects of gonadal steroid and peptide hormones on $\mathrm{FSH}$ and $\mathrm{LH}$ responses to $\mathrm{GnRH}$, and differences in the halflives of the two hormones. Moreover, while LH is stored within the gonadotrope and its secretion is largely dependent on $\mathrm{GnRH}, \mathrm{FSH}$ tends to be constitutively secreted and its secretion is more dependent on biosynthesis. 


\section{GnRH peptide agonist and antagonist analogues}

The primary structure of $\mathrm{GnRH}$ isolated from pigs and sheep was initially thought to be conserved throughout vertebrates. However, the demonstration that bird, fish and reptile $\mathrm{GnRH}$ had different properties ${ }^{17}$ led to the structural elucidation of a novel form in chickens ${ }^{18,19}$ and subsequently to an array of structures in vertebrates and invertebrates ${ }^{17,20-34}$ (Figure 2). These structural variants reflect "experiments of nature" over at least 600 million years of evolution and provide insight into conserved and functionally important residues and domains. The structures reveal that the amino and carboxyl terminal domains are highly conserved, indicating that they are important for receptor binding and activation. Gly ${ }^{6}$ in the middle of the molecule is also highly conserved in vertebrates and facilitates folding of the peptide (see below). The amino acid in position eight is the most variable, with $\operatorname{Arg}^{8}$ in mammalian $\mathrm{GnRH}$ being essential for high affinity binding to mammalian receptors through interaction with an acidic residue in extracellular loop three of the $\mathrm{GnRH}$ receptor ${ }^{35}$.

Physico-chemical studies utilising tryptophan fluorescence, conformational memory simulations, nuclear magnetic resonance and ion mobility mass spectrometry have indicated that mammalian $\mathrm{GnRH}$ assumes a folded confirmation around Gly ${ }^{6}$. This is depicted in the NMR structure in Figure 3 . In this conformation the amino and carboxyl termini are closely apposed, allowing these conserved domains to bind and activate the receptor. The achiral Gly ${ }^{6}$ which facilitates the formation of a $\beta$-II' type turn is conserved in most vertebrates and substitution of Gly ${ }^{6}$ with chiral amino acids, as is present in the GnRHs of jawless fish and invertebrates, leads to a large decrease in binding affinity at the mammalian GnRHR. Conversely, the substitution of the chiral amino acids in position six of sea squirt GnRHs with Gly increases the binding affinity of these $\mathrm{GnRHs}$ at the mammalian receptor ${ }^{36}$. If Gly ${ }^{6}$ is substituted with a D-amino acid the $\beta$-II' confirmation is enhanced and binding affinity is increased ${ }^{37}$. This feature is incorporated in all GnRH analogues (Figure 4). Substitutions of $\mathrm{Gly}^{6}$ with D-amino acids containing large aromatic side chains, such as D-Trp (as in the drug, Triptorelin), increases binding affinity compared with GnRH by about 100-fold while substitution with D-Leu (as in the drug, Leuprolide) only increases affinity \pm 10 -fold. Substitutions at this position have the added advantage of conveying resistance to proteolytic cleavage. Incorporation of D-amino acids with large hydrophobic side chains (e.g. D-Trp) results in 
a

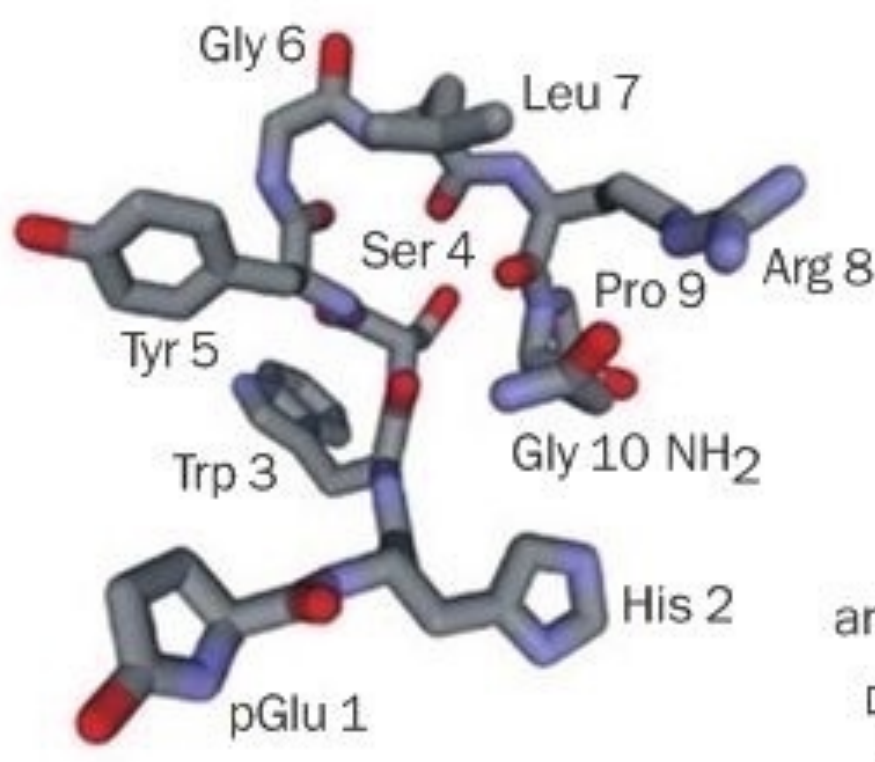

b

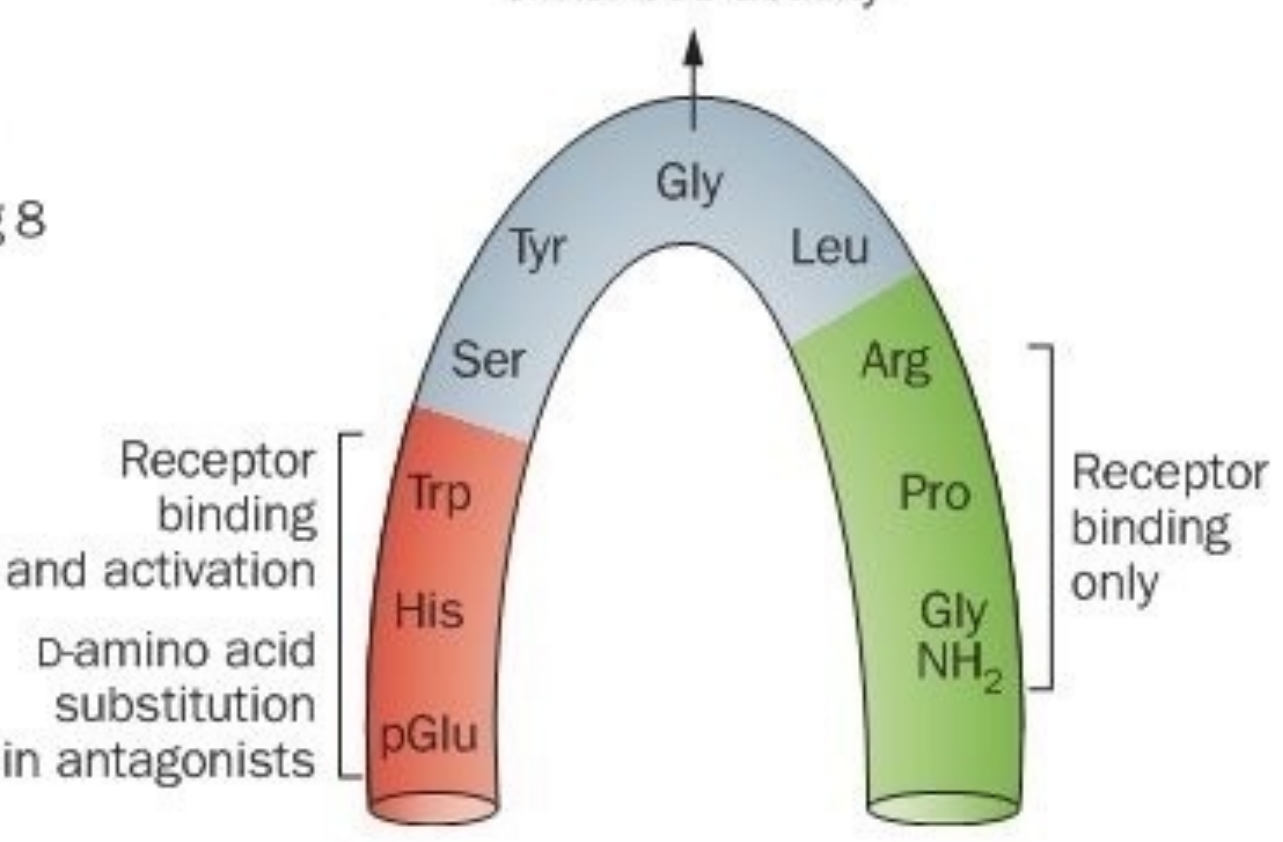

Figure 2 | The 3D structure of GnRH. a | NMR structure of mammalian GnRH showing the $\beta-I I '$ bend around glycine in position 6 . The $\beta$-II' type turn occurs when a region of the peptide involving four consecutive amino acids folds back on itself by nearly $180^{\circ}$. b | Schematic representation of mammalian $\mathrm{GnRH}$ in the folded conformation, in which it is bound to the GnRH pituitary receptor. The molecule is bent around the achiral glycine in position 6 . Substitution with D-amino acids in this position stabilizes the folded conformation, increases binding affinity and decreases metabolic clearance. This feature is incorporated in all agonist and antagonist analogues. The amino (red) and carboxyl (green) termini are involved in receptor binding. The amino terminus alone is involved in receptor activation and substitutions in this region produce antagonists. Abbreviation: $\mathrm{GnRH}$, gonadotropin-releasing hormone. Part a reprinted from Front. Neuroendocrinol. 29 (1), Millar, R. P. et al. Diversity of actions of GnRHs mediated by ligand-induced selective signaling, 17-35, (C) 2007, with permission from Elsevier. ${ }^{52}$ Part b adapted from Millar, R. P. in Reproductive Medicine: Molecular, Cellular and Genetic Fundamentals (ed. Fauser, B. C. J. M.) (Parthenon Publishing, Lancaster, 2002). 
binding to plasma proteins such as albumin, thus further enhancing half-life in the circulation and decreasing metabolic clearance ${ }^{38}$. Substitution of the carboxyl terminal Gly. $\mathrm{NH}_{2}$ with alkyl moieties (e.g. ethylamide) conveys further resistance to proteolysis without compromising binding affinity ${ }^{38}$. Thus, these elements form the basis of all $\mathrm{GnRH}$ peptide analogues.

Studies involving systematic substitutions of all $\mathrm{GnRH}$ amino acids established that substitutions in the amino terminal domain resulted in retention of binding affinity but reduced receptor activation and represented the first antagonists ${ }^{38}$. Further experimentation with multiple amino terminal domain substitutions, particularly with unnatural D-amino acids (such as D-Napthyl alanine) produced analogues with very high binding affinity $(<1 \mathrm{nM})$ and full antagonist properties. All antagonists have substitutions with bulky hydrophobic D-amino acids in positions 1,2 and 3 (and some in 4) which maintain high binding affinity but ablate GnRHR activation ${ }^{38,39}$.

$\mathrm{GnRH}$ agonists and antagonists which have entered the clinic are shown in Figure 4.

\section{Non-peptide analogues}

The development of non-peptide orally bioavailable $\mathrm{GnRH}$ antagonists have been pursued by most large pharmaceutical companies as well as a number of small biotech companies in order to overcome the requirement of injection of peptide antagonists. Furthermore, orally active molecules provide the potential for titrating the dose to accomplish partial inhibition of sex steroid hormones which cannot be achieved with injectable peptide antagonists. Partial inhibition is desirable in certain hormone-dependent diseases such as endometriosis and benign prostatic hyperplasia to ameliorate the pathology without inducing the unwanted side effects resulting from total gonadal steroid inhibition, such as bone loss and hot flushes. Fourteen chemical classes of compounds have been developed as $\mathrm{GnRH}$ antagonists. These include derivatives of thieno[2,3-d]pyridine-4-one, quinolin-2-one, indole, pyrrolo[1,2-a]pyrimidin7-one, imidazole[1,2-a]pyrimidin-5-one, thieno[2,3-d]pyrimidin-2,4-dione, furamide, pyrimidin-2,4-dione, benzimidazole, and 1,3,5-triazine-2,4,6-trione. These derivatives and their pharmacological properties have been thoroughly reviewed ${ }^{40}$. 
It appears that the binding sites of the non-peptide $\mathrm{GnRH}$ antagonists overlap with each other but also to some extent with the orthosteric binding site of $\mathrm{GnRH}$. Thus, Asp ${ }^{302}, \mathrm{Asn}^{212}$ and $\mathrm{Tyr}^{283 / 284}$ of the GnRHR, which were all identified as interacting sites for $\mathrm{GnRH}$, are proposed sites of interaction with the nonpeptide antagonists $^{3,41,42}$. Figure 5 shows a summary of the optimal pharmacophore extracted from the data.

Of the very large spectrum of non-peptide antagonists which have been developed and patented, only compounds from Neurocrine Biosciences and Takeda have entered the clinic. (Figure 5). These compounds exhibit high receptor binding affinity, good bioavailability and good pharmacokinetic and pharmodynamic profiles ${ }^{43,44}$. Neurocrine Biosciences have also demonstrated good dose-response relationships which allows dosing for partial $\mathrm{LH}$ and steroid suppression ${ }^{45}$. The primary therapeutic target of these compounds is currently endometriosis but there is a clear possibility for application in PCOS and IVF, as well as for partial androgen suppression in benign prostatic hyperplasia (see "Therapeutic uses of GnRH analogues" below). While these small molecule GnRH antagonists have the advantage of oral activity and dosing to achieve the desired degree of steroid hormone inhibition, the peptide analogues have potentially fewer off-target side effects than the small molecules as they are modified versions of the natural hormone which has been highly selected during evolution to specifically target the cognate receptor.

Compared to other GnRHRs, cell surface expression of the human receptor is low ${ }^{46}$ and this is further exacerbated in a number of loss-of-function mutations in the GnRHR have been reported in patients suffering from hypogonadotropic hypogonadism ${ }^{3}$. The majority of these are inactive as a result of misfolding of the receptor and a failure to traffic to the cell surface. Some non-peptide $\mathrm{GnRH}$ analogues are able to penetrate into the cell, bind to the nascent receptors and stabilise the folding of the mutant GnRHRs; thereby acting as 'pharmacoperones' to increase mutant receptor cell surface expression (see 47, 48 for comprehensive reviews). 


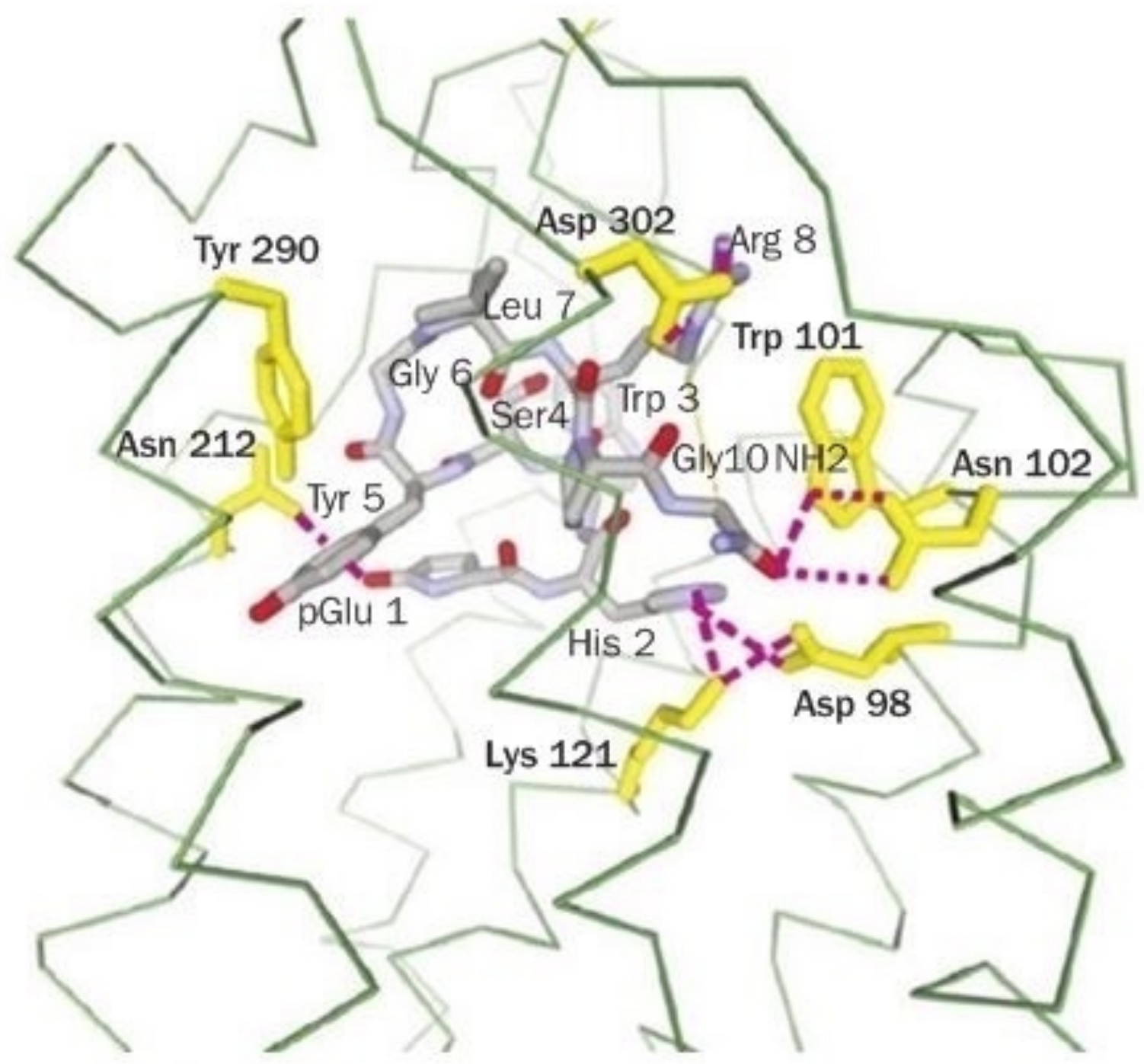

Figure 5 | Docking of the NMR GnRH structure to the human $\mathrm{GnRH}-\mathrm{R}$, in which only the essential elements are shown, to reveal the interactions of $\mathrm{GnRH}$ in a folded conformation with the receptor. pGlu interacts with Asn 212, His 2 with Lys 121/Asp 98, Tyr 5 with Tyr 290, Arg 8 with Asp 302 and Pro 9 Gly 10-NH2 with Trp 101/Asn 102. Abbreviations: $\mathrm{GnRH}$, gonadotropin-releasing hormone; GnRH-R, gonadotropin-releasing hormone receptor. Front. Neuroendocrinol. 29 (1), Millar, R. P. et al. Diversity of actions of GnRHs mediated by ligand-induced selective signaling, 17-35, (c) 2007, with permission from Elsevier. ${ }^{52}$ 
Although a large range of small molecule $\mathrm{GnRH}$ antagonists have been developed, so far there appears to have been no attempt to produce non-peptide agonists.

\section{GnRH/GnRH receptor interactions and desensitisation}

The $\mathrm{GnRH}$ receptor (GnRHR) was first cloned from a mouse gonadotrope cell line ${ }^{49}$ and subsequently from a large range of mammals, vertebrates and invertebrates ${ }^{3,33}$. The receptor is a member of the rhodopsin family of G-protein coupled receptors (GPCRs) with characteristic seven transmembrane (TM) domains connected by extracellular loop (EC), and intracellular loop (IC) domains. A unique feature is the absence of a carboxyl terminal tail which is responsible for rapid (within minutes) ligand-induced desensitisation of GPCR's. Thus, the GnRHR is not rapidly desensitised, probably to facilitate prolonged LH secretion which is necessary for ovulation ${ }^{50}$. Nevertheless, prolonged exposure (1-3 weeks) to $\mathrm{GnRH}$ agonists induces a decline in circulating gonadotropin and sex steroids in humans. This is a slow pharmacological phenomenon, in contrast to the rapid desensitisation (within minutes) seen with most other GPCRs which is designed to terminate signalling. The application of long term desensitisation utilising $\mathrm{GnRH}$ agonists is described under "therapeutic applications of $\mathrm{GnRH}$ analogues" below.

The mechanism of $\mathrm{GnRH}$ agonist desensitisation is widely regarded as being through $\mathrm{GnRH}$ receptor "down regulation". This is evidently incorrect as the actions of the agonists would be nullified if there was a decline of $\mathrm{GnRH}$ receptors on which to act. The mechanisms of desensitisation are multiple and include uncoupling to G-protein and downstream signalling through calcium mobilisation and protein kinase activation which cannot be enumerated here. Suffice to say that the gonadotrope continues to respond to $\mathrm{GnRH}$ agonist but fails to elaborate and secrete biologically active gonadotropins. This is evident from the elevated circulating alpha gonadotropin subunit in patients on long term agonist treatment but diminished alpha/beta gonadotropin biologically active heterodimers ${ }^{51}$. Thus effective receptor is present but recruitment of biosynthetic/exocytotic machinery is altered. 


\section{a}

Acetylation to potentially decrease degradation

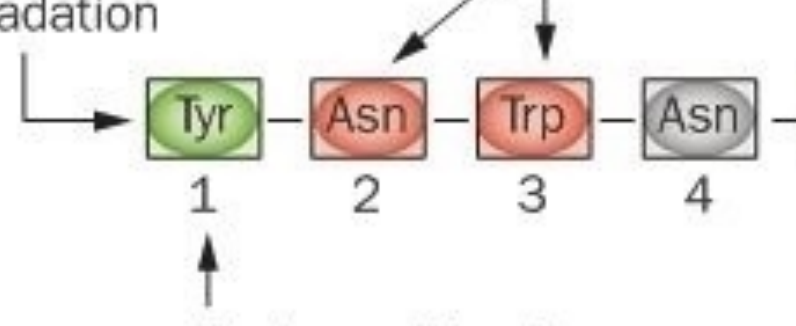

Replace with D-Tyr or D-Ala to enhance antagonism
Critical for binding

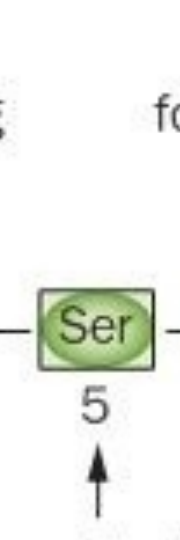

Replace with

Gly or D-Ser for antagonism
Critical

for binding

b

Critical

for binding<smiles>N#Cc1c(-c2cccc(NC(=O)CCN)c2)cc(-c2ccc(F)cc2O)nc1NC(=O)c1ccco1</smiles>

Figure 6 | Kisspeptin analogues. a | Critical residues in Kp-10. Residues that are important for receptor binding and retained in analogues are shown in red and residues involved in receptor activation, and thus are substituted in antagonists, are shown in green. Residues shown in grey could be substituted without major effects. The substitution of serine at position 5 with glycine allowed flexibility and greater tolerance of the green substitutions required for antagonist activity. b | Nonpeptide small-molecule kisspeptin antagonist 15a, which shows high binding affinity for GPR54 and antagonism of kisspeptin in vitro and in vivo. Abbreviation: Kp-10, kisspeptin-10. 
Knowledge of the three dimensional structure of the GnRHR is essential for a complete understanding of its molecular functioning and binding of $\mathrm{GnRH}$. In the absence of a crystal structure of the $\mathrm{GnRHR}$, molecular models of the receptor based on the crystal structures of the other GPCRs such as rhodopsin and the $\beta_{2}$-adrenergic receptor have been constructed ${ }^{3,52}$. The validity of the GnRHR structural model has been tested by extensive mutagenesis to identify putative interacting residues. In this way a reliable model of the GnRHR has been built and binding sites of $\mathrm{GnRH}$ in the receptor identified. The NMR structure of $\mathrm{GnRH}$ has been satisfactorily docked to the $\mathrm{GnRH}$ receptor structure to accommodate all of the interactions of the ligand and receptor ${ }^{52}$ (Figure 6). The cloning of the GnRHR has been crucial for the development of non-peptide antagonists and knowledge of the interaction of $\mathrm{GnRH}$ with the receptor has guided the development of $\mathrm{GnRH}$ analogues.

\section{Therapeutic applications of GnRH analogues}

Pulsatile delivery of $100 \mu \mathrm{g} / \mathrm{h}$ of native $\mathrm{GnRH}$ (to simulate hypothalamic release) has been successfully used to stimulate fertility in hypothalamic hypogonadism resulting from congenital conditions such as Kallman's syndrome and nutritional conditions such as anorexia nervosa, obesity and diabetes mellitus. This treatment modality is also effective in stimulating testis descent in cryptorchidism and delayed puberty ${ }^{25,53-58}$.

In contrast to these stimulatory uses of native $\mathrm{GnRH}$, both agonists and antagonists are administered to inhibit gonadotropins and sex steroid secretion; agonists through gonadotrope desensitisation and antagonists through direct inhibition of endogenous $\mathrm{GnRH}$ binding and activation of the $\mathrm{GnRH}$ receptor. $\mathrm{GnRH}$ analogues are therefore extensively employed in treating hormone-dependent diseases and in preventing ovulation and aiding oocyte retrieval in assisted reproductive technologies such as IVF (Table 2). As such they constitute a market in excess of $\$ 2$ billion. 


\title{
Pulsatile GnRH (stimulation)
}

\author{
Infertility \\ Cryptorchidism \\ Delayed puberty
}

\section{GnRH agonist and antagonist (inhibition)}

Contraception

Inhibition of ovulation and spermatogenesis with add-back sex steroid hormones

Hormone-dependent diseases

Prostatic cancer

Benign prostatic hyperplasia

Breast cancer

Endometriosis

Uterine fibroids

Premenstrual syndrome

Polycystic ovarian syndrome

Hirsutism

Acne vulgaris

Precocious puberty

Acute intermittent porphyria

Infertility

Inhibition of endogenous gonadotropin together with controlled administration of exogenous gonadotropin, especially in induction of ovulation in assisted reproduction (e.g. IVF)

A disadvantage of $\mathrm{GnRH}$ agonists is the initial stimulation of gonadotropin and sex steroids for the first 1 2 weeks prior to the onset of desensitisation. This feature results in the "flare" of the condition in hormone-dependent diseases. The flare period can be managed by concurrent administration of steroid antagonists or inhibitors of steroid biosynthesis. A further disadvantage is that desensitisation with agonists requires a longer treatment period when used for the induction of follicle development and oocyte retrieval in IVF. Thus agonists are being replaced with antagonists for this procedure. 
$\mathrm{GnRH}$ antagonists do not induce disease flare as there is an immediate inhibition of gonadotropin and sex steroids, with a brief delay corresponding to the half-life of the hormones. First generation $\mathrm{GnRH}$ antagonists produced a concerning histaminic reaction. It materialized that this was due to an amino acid basic-x-basic amino acid motif. Consequently, current antagonists which have entered the clinic avoid this structural feature and are free of histaminic activity ${ }^{59}$. The main disadvantage of peptide $\mathrm{GnRH}$ antagonists, when compared with agonists, is that much higher doses are required to continually compete with endogenous $\mathrm{GnRH}$ which increases due to the decline in sex steroids and concomitant removal of negative feedback on $\mathrm{GnRH}$ secretion. Thus, monthly depot preparations of $\mathrm{GnRH}$ antagonist contain about $100 \mathrm{mg}$ in contrast to monthly preparations of 3-5 mg GnRH agonists.

A perceived disadvantage of $\mathrm{GnRH}$ peptide analogues is the requirement to administer by injection as they are proteolytically cleaved in the digestive tract and therefore not orally bioavailable. However, this is compensated by formulating as slow release depot preparations which requires infrequent administration (1-12 monthly) and ensures patient compliance. GnRH agonists such as Triptorelin, Zoladex and leuprolide are formulated as slow release depot preparations in biodegradable polymers (e.g. polyglycyl lactide copolymer). When injected intramuscularly these preparations (about 3-5 mg) release approximately $100 \mu \mathrm{g} /$ day for a month. Some preparations (e.g. Histrelin) are capable of suppressing gonadotropin for 12 months ${ }^{60}$. GnRH antagonists have been similarly formulated.

As the objective of $\mathrm{GnRH}$ analogue therapy in hormone-dependent diseases is to lower sex steroid hormones, expected side effects in prolonged treatment are hot flushes, vaginal dryness, irregular vaginal bleeding, loss of libido, decreased lean body mass and bone loss. These symptoms may be alleviated by intermittent treatment with $\mathrm{GnRH}$ analogue or by "add back" therapy of appropriate sex steroid (e.g. oestrogen in men being treated for prostatic cancer who experience hot flushes and bone loss $\left.{ }^{61-63}\right)$. A novel approach to the undesired side effects of $\mathrm{GnRH}$ analogues is the development of bifunctional conjugates of $\mathrm{GnRH}$ analogue in which the position $6 \mathrm{D}$-amino acid is conjugated to the appropriate sex steroid. These conjugates retain full $\mathrm{GnRH}$ analogue and steroid activity within a single molecule ${ }^{64}$. 
Of all the therapeutic applications for $\mathrm{GnRH}$ analogues, their use in prostatic cancer is by far the greatest, and they are the preferred therapeutic treatment for this condition ${ }^{65}$. There is a marked increase in survival, reduction in prostate-specific antigen (PSA) and pain. GnRH analogues are also employed in almost all cycles for IVF treatment to avoid the spontaneous LH surge and loss of oocytes before laproscopic surgery for oocyte retrieval ${ }^{66}$. In all other applications of $\mathrm{GnRH}$ analogues, alternative therapeutic approaches are available (for details the reader is referred to a review ${ }^{67}$ ).

Among benign conditions, endometriosis has a prevalence of $6-10 \%$ of all women and $20-40 \%$ of infertile women. Improvement of pain is reported in $75 \%$ of women on $\mathrm{GnRH}$ analogue therapy, but there appears to be no improvement in pregnancy rates. $\mathrm{GnRH}$ analogue therapy has also been reported to be beneficial in a range of other hormone-dependent conditions in women including PCOS (the most common endocrine disorder in women ${ }^{68}$ ), uterine fibroids (the most common solid tumour in women) ${ }^{69}$ and dysfunctional uterine bleeding ${ }^{70}$.

$\mathrm{GnRH}$ analogues have also been employed with success in hormone-dependent malignancies. $\mathrm{GnRH}$ analogue combined with anti-oestrogen was more effective than either treatment alone in metastatic breast cancer in premenopausal women with oestrogen positive disease ${ }^{71}$. Ovarian and endometrial cancers apparently express $\mathrm{GnRH}$ and $\mathrm{GnRHR}$ and there are indications of direct cell cycle arrest and efficacy in clinical trials using $\mathrm{GnRH}$ analogues ${ }^{72,73}$. A number of studies have also utilised $\mathrm{GnRH}$ analogues to inhibit gonadal activity in an attempt to protect the gonads prior to cytotoxic chemotherapy but the effectiveness is still uncertain.

\section{KP analogues}

\section{Background}

Although the $\mathrm{GnRH}$ neurone is the final neuroendocrine conduit for the influence of diverse internal and external factors regulating reproduction, the absence of receptors for these inputs on $\mathrm{GnRH}$ neurons 
presented a conundrum. In particular sex steroid hormone receptors which are required for negative and positive feedback by steroids on $\mathrm{GnRH}$ secretion are largely absent from $\mathrm{GnRH}$ neurons. This suggested the existence of steroid-responsive neurons which regulate $\mathrm{GnRH}$ neurons. A breakthrough in identifying such neurons occurred with the observation that inactivating mutations in genes encoding the human and mouse kisspeptin (KP) receptors (GPR54/Gpr54) resulted in a failure to progress through puberty ${ }^{6,7}$. An inactivating mutation in the human gene encoding KP (KiSS-1) also resulted in a failure to achieve puberty ${ }^{8}$.The discoveries that the KPs and their cognate receptor GPR54 play a key neuroendocrine role in the regulation of reproduction ${ }^{7}$ is regarded as a milestone of equivalent importance to the discovery of $\mathrm{GnRH}$ more than three decades ago.

The KPs are members of a group of peptide hormones known as RF-amides characterized by an ArgPhe- $\mathrm{NH}_{2}$ motif at the carboxyl-terminus. RF-amides signal through cognate GPCRs which are involved in numerous physiological and pathophysiological processes including control of food intake, pain, inflammatory responses, development and metabolism ${ }^{74}$. The KiSS-1 gene transcribes a 145 amino acid secretory polypeptide with a signal sequence followed by 119 amino acid sequence which is processed to a 54 amino acid peptide in man. KP was initially dubbed metastin due to its activity in inhibiting metastasis of melanoma cells ${ }^{75,76}$. The human 54 amino acid peptide and rodent 52 amino acid peptide are further proteolytically processed to C-terminal peptides of 14,13 and 10 amino acids, all of which are biologically active ${ }^{75}$. The 10 amino acid peptide (KP-10) has full intrinsic biological activity 76, 77 . However the 54 or 52 amino acid peptides have longer half-lives and therefore increased LHreleasing activities than the shorter forms in vivo ${ }^{78,79}$.

KP-10 is a potent stimulator of $\mathrm{LH}, \mathrm{FSH}$ and gonadal steroid secretion when administered both centrally and systematically ${ }^{80-83}$. KP stimulation of gonadotropins is ablated by co-administration of $\mathrm{GnRH}$ antagonist; demonstrating that $\mathrm{KP}$ acts through the stimulation of $\mathrm{GnRH}$ secretion ${ }^{84}$. Moreover, $\mathrm{GnRH}$ neurons express GPR54 ${ }^{85}$ and KP stimulates GnRH secretion ${ }^{86}$. Intravenous (i.v.) infusion of KP-54 to normal men increases circulating $\mathrm{LH}$ and $\mathrm{FSH}{ }^{87}$. Acute i.v. administration of $\mathrm{KP}-10$ has similar stimulatory effects on gonadotropin secretion in men over a dose range of 0.01 to $1 \mu \mathrm{g} / \mathrm{kg}{ }^{88,89}$. The 
stimulatory effect of KP administration to normal women is greatest during the pre-ovulatory phase of the menstrual cycle ${ }^{90}$.

Importantly, KP neurons express steroid hormone receptors ${ }^{91-94}$, and gonadectomy in rodents increases detectable KP cell numbers and mRNA expression levels in the arcuate nucleus (ARC), while steroid replacement reverses this. While KP neurons in the ARC mediate this steroid negative feedback control on $\mathrm{GnRH}$ neurons, another population in rodents in the anteriorventral paraventricular nucleus (AVPV) mediates positive feedback, resulting in the ovulatory LH surge ${ }^{93-96}$. This anatomically-linked functional dimorphism of KP neurons is not evident in sheep and monkeys as both types of neurons appear to be localized in the $\operatorname{ARC}^{91,97,98}$.

In order to ensure survival of offspring, reproduction is finely tuned to the availability of nutrients and metabolic status. KP appears to have a major mediating role in the dialogue between nutrition and metabolism with reproduction (see review ${ }^{5}$ ). This relationship is of particular significance in the context of the rising global prevalence of obesity and secondary pathologies such as diabetes. There are now substantial data supporting a central role for the KP/GPR54 system in mediating the effects of metabolism on the reproductive system ${ }^{5,99,100}$. A link between leptin secretion from adipose tissue and KP gene expression is suggested by the observation that KiSS-1 expression in the ARC is reduced in castrated leptin-deficient $o b / o b$ mice, and is increased by administration of leptin. Although initial studies reported expression of leptin receptors on KP neurons ${ }^{101}$, subsequent studies have refuted this claim. Deletion of leptin receptor in hypothalamic kisspeptin neurones in mice had no effect on puberty or fertility, indicating that direct leptin signaling in KiSS-1 neurons is not required for these processes. However, bilateral lesions of the ventral premammillary nucleus (PMV) of ob/ob mice blunted the ability of exogenous leptin to induce sexual maturation ${ }^{102}$. Experimental diabetes mellitus induced by Streptozotocin results in reduced KiSS-1 mRNA expression and gonadotropin secretion ${ }^{103}$. Fasting reduces KiSS-1 mRNA expression in the rat hypothalamus, and KP administration reverses starvationinduced hypogonadotropism ${ }^{104}$, while GPR54 mRNA expression is similarly affected ${ }^{101}$. Based on these animal studies, hypotheses proposing a role for KP signaling in mediating hypogonadotropic 
hypogonadism in diabetes mellitus and obesity in humans have been articulated ${ }^{88}$. Metabolic effects on reproduction in humans which may involve KP dysregulation, include hypothalamic amenorrhea, (anorexia nervosa being an extreme example), and PCOS, which is characterized by increased LH pulse frequency and is often associated with obesity ${ }^{68}$. For detailed reference to the diverse physiological and pathophysiological regulation of KP the reader is referred to comprehensive reviews ${ }^{76,105,106}$.

\section{$K P$ peptide agonist and antagonist analogues}

Two approaches are employed in the development of peptide analogues. In alanine scanning, each residue is systematically substituted with alanine which lacks a functional side chain, thus revealing whether the side chain is of importance or not. This approach revealed that alanine substitutions for Phe ${ }^{6}$ and $\mathrm{Phe}^{10}$ of KP-10 significantly reduced binding and activation of GPR54 in vitro and in vivo, indicating that aromatic side chains groups in amino acids in these positions are required for activity ${ }^{107,} 108$. Substitution of $\mathrm{Arg}^{9}$ with alanine also significantly decreased binding and activation as did substitutions of $\mathrm{Leu}^{8}$. Thus, $\mathrm{Phe}^{6}, \mathrm{Arg}^{9}$ and $\mathrm{Phe}^{10}$ appears to constitute a binding pharmacophore with proposed stacking of phenyl rings of $\mathrm{Phe}^{6}$ and $\mathrm{Phe}^{10}$ flanked by $\mathrm{Arg}^{9}$ and $\mathrm{Leu}^{8}$ with side chains orientated on the opposite side of the peptide ${ }^{107}$. Another approach utilizing knowledge of KP-10 structure involves conservative changes at target positions, such as changing the side chain but not the overall charge of a residue, substituting L-amino acids with D-amino acids to assess the positioning of side chains and making radical structural changes to change overall charge or flexibility of the analogue. Substitution of $\mathrm{Arg}^{9}$ and $\mathrm{Phe}^{10}$ led to a loss in binding, confirming the importance of these conserved residues ${ }^{109,}{ }^{110}$. These authors also truncated KP to the last 5 amino acids which retained some binding but ablated signaling capacity. Substitutions in this pentapeptide failed to improve binding and further exploration was abandoned in favor of making substitutions in the full length KP-10.

Researchers at Takeda Pharmaceutical Company pursued the development of KP peptide agonists for anticancer and hormone-dependent disease by systematic natural and unnatural amino acid substitution 111, 112. Amongst a large number of analogues it is evident from ensuing patents that the critical pharmacophore of $\mathrm{Phe}^{6}, \mathrm{Arg}^{9}$, and Phe10 mentioned above is retained or altered with conservative 
amino acid substitutions. Other positions in the KP-10 sequence were subject to a range of substitutions to provide resistance to degradation and improved pharmacokinetics. A series of agonists at GPR54 were produced with potent inhibition of cancer cell growth and stimulation of reproductive hormones ${ }^{111}$, 112. Two of these peptide agonists (KISS1-305 and TAK-448) have been studied in depth for short term gonadotropin and steroid hormone stimulation and long term inhibition through desensitization in rats ${ }^{113}$. The mechanism of desensitization appeared to be predominantly at the level of the $\mathrm{GnRH}$ neurone. With both analogues testosterone was reduced to castration levels within three days and remained depleted throughout the four week treatment. Remarkably, the suppression of testosterone was apparently faster and more pronounced, and reproductive organ weights more reduced than after administration of the $\mathrm{GnRH}$ analogue, Leuprolide. This result is unexpected as kisspeptin stimulation of LH in humans and a number of animal studies is much less than that of $\mathrm{GnRH}$ and kisspeptin antagonists, and only partially suppresses $\mathrm{LH}$, suggesting that there is an element of $\mathrm{GnRH}$ secretion which is kisspeptin independent 110,114

In all of the studies on the physiological and pathophysiological regulation of $K P$, the end point measures were KP mRNA and/or KP peptide in tissue. There is therefore no direct evidence that these manipulations alter the secretion of KP. An exception is the single study demonstrating that KP antiserum inhibits the ovulatory LH surge ${ }^{115}$, implying that increased KP secretion elicits the surge. To directly elucidate the role of KP secretion and GPR54 activation in physiological processes, the development of KP antagonists is essential. An understanding of the structure of KP is a key point of departure in this endeavor. KP-54 and the smaller processed peptides of 14, 13 and 10 amino acids in length have been shown to bind to and activate the receptor with equal potency ${ }^{77}$. Therefore, the minimal 10 amino acid fragment of the carboxyl-terminus has been used to analyse the structure of KP and to design KP antagonists. The activation domain is thought to reside within the 5 most aminoterminal residues which is dominated by hydrophobic residues while the binding domain resides predominantly within the five most carboxyl-terminal residues which contains both hydrophobic and charged residues as described earlier. 
NKB: $\quad$ Asp - Met - His - Asp - Phe - Phe - Val - Gly - Leu - Met $-\mathrm{NH}_{2}$

Senktide:

Succinyl - Asp - Phe - MePhe - Gly - Leu - Met - $\mathrm{NH}_{2}$

[MePhe ${ }^{7}$ NKB: Asp - Met - His - Asp - Phe - Phe - MePhe - Gly - Leu - Met - $\mathrm{NH}_{2}$

b

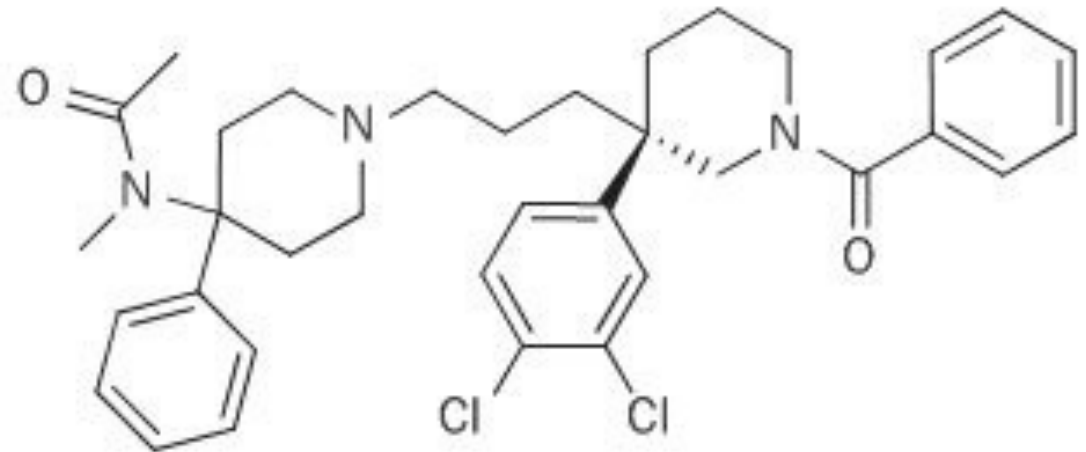

Osanetant

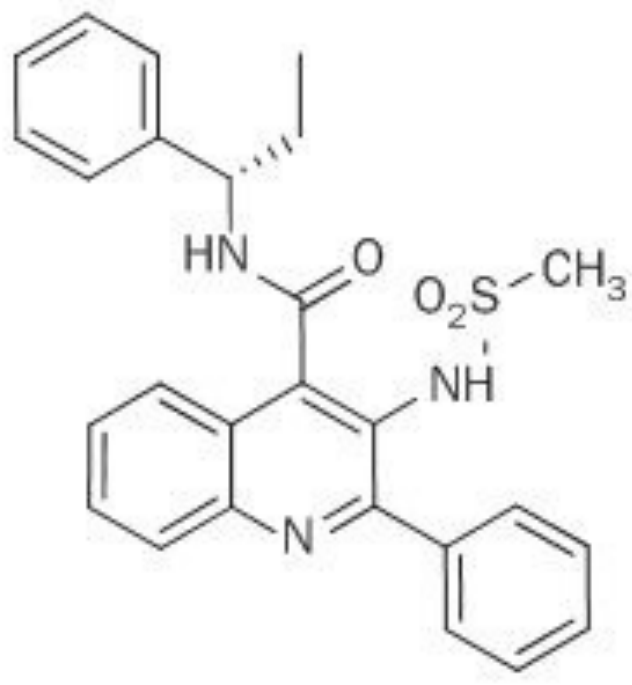

AZD2624

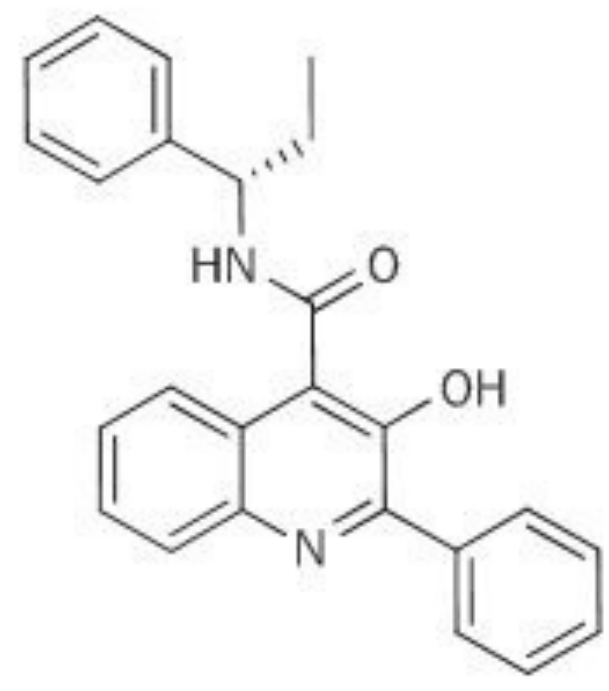

Talnetant

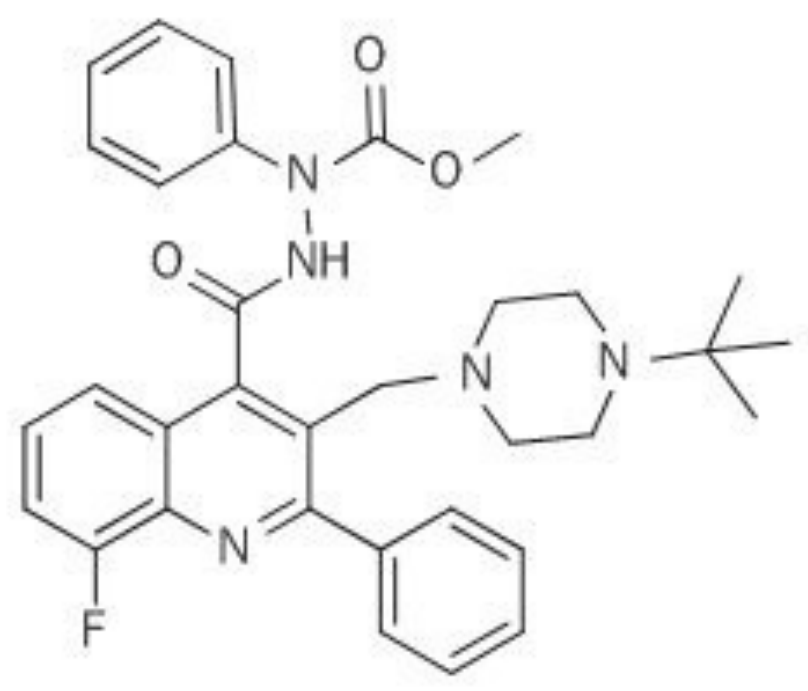

$8 \mathrm{~m}$

Figure 7 | Neurokinin B analogues. a | Peptide agonist analogues specific for TACR3. Senktide is an analogue of substance $P$ which is highly selective for TACR3 whilst [MePhe7] NKB is not as selective for TACR3 and can also activate the TACR2 at high concentrations. b | Nonpeptide antagonists highly selective for TACR3. Osanetant, talnetant and AZD2624 have all been tested in man for nonreproductive applications. Thus, proof of concept reproductive studies would be insightful. The compound $8 \mathrm{~m}$ has not yet entered the clinic. Abbreviations: NKB, neurokinin B; TACR3, tachykinin receptor 3; TACR2, tachykinin receptor 2 . 
During the course of systematic substitution of each of the amino acids (34 analogues) a consensus sequence emerged for analogues which retained binding but failed to elicit signaling, and antagonised KP-10 stimulations of $\mathrm{Ca}^{2+}$ and/or inositol phosphate production in cells expressing the human GPR54 . The major conclusions of the studies are summarized in Figure 7. Most importantly, substitution of Ser ${ }^{5}$ with the achiral Gly appears to create flexibility within the peptide and improved tolerance of other substitutions directed at antagonism.

The most valuable additional substitution for antagonism was the replacement of Leu ${ }^{8}$ with D-Trp. This peptide (peptide 210) exhibited high binding affinity $(7.3 \mathrm{nM})$ and inhibition of $10 \mathrm{nM} \mathrm{KP}-10$ stimulation of inositol phosphate generation $(30 \mathrm{nM})$. This peptide was acetylated at the amino-terminus in an attempt to reduce degradation and was effective in inhibiting $\mathrm{LH}$ in animal models ${ }^{109}$. An additional substitution of $\mathrm{Tyr}^{1}$ with acetylated D-Ala (peptide 234) produced a potent antagonist in a wide range of ex vivo and in vivo animal studies ${ }^{109,110 .}$

In order to create an analogue capable of penetrating the blood brain barrier the penetratin sequence was added to the amino-terminus of peptide 234 (peptide 271). Systemic administration of this antagonist inhibited i.c.v. and i.v. kisspeptin stimulation of $\mathrm{LH}$ in rats ${ }^{116}$. It may, therefore, be a valuable tool with which to compare effects with peptide 234 and tease out potential differences in activities at GnRH nerve terminals (peptide 234) as opposed to both terminals and cell bodies (peptide 271). Other high activity antagonists were peptide 273 (D-Ser ${ }^{6}$ substitution of peptide 234) and peptide 276 (D-Leu ${ }^{6}$ substitution of peptide 234). An additional 54 analogues were synthesised, including substitutions with unnatural amino acids, which confirmed the general consensus sequence for antagonist structure.

\section{Non-peptide analogues}

Small molecule non-peptide KP antagonists derived from a 2-acylamino-4,6-diphenylpyridine scaffold have been developed. Kobayashi et al. adopted a combinatorial chemistry approach to identify a 2-furoyl 
group as the most active antagonist of all tested 2-acylamino-4,6-diphenylpyridine derivatives ${ }^{117}$. They identified compound $9 \mathrm{I}$ (Fig. 7a) with an $\mathrm{IC}_{50}$ value of 3.7nM for receptor binding to GPR54 and with high antagonistic activity against KP-10 stimulated intracellular calcium release ${ }^{117}$. Further optimization yielded compound 15a (Fig. 8b) containing a piperazine ring which exhibited high affinity binding to both human and rat GPR54 with $\mathrm{IC}_{50}$ values of $3.6 \mathrm{nM}$ and $15 \mathrm{nM}$, respectively. Compound $15 \mathrm{a}$ exhibited high antagonistic activity against KP-10 stimulated calcium release in $\mathrm{CHO}$ cells stably expressing GPR54 (Fig. 7c) ${ }^{118}$.

\section{Interrogating KPs role in physiology using antagonists}

The efficacy of the peptide antagonists peptide 210 and peptide 234 was established by the demonstration of their ability to inhibit KP stimulation of LH in male rats and mice ${ }^{109}$. However, KP antagonist did not lower $\mathrm{LH}$ to below basal unlike $\mathrm{GnRH}$ antagonists, suggesting a component of $\mathrm{GnRH}$ secretion is independent of KP. Peptide 234 directly inhibited KP stimulation of GnRH neuron firing in mouse brain slices at low concentration $(1 \mathrm{nM})$ and, in pubertal female rhesus monkeys, peptide 234 inhibited $\mathrm{GnRH}$ pulses but not basal levels ${ }^{109}$. This provides direct evidence for a role for KP in $\mathrm{GnRH}$ secretion at puberty. In another study in prepubertal female monkeys, GnRH was suppressed for 90 minutes by peptide 234 suggesting that there is a lower KP tone ${ }^{119}$. Peptide 234 was also effective in suppressing $\mathrm{LH}(\mathrm{GnRH})$ pulsatility in ovariectomised ewes without affecting basal $\mathrm{LH}^{109}$ and decreased LH pulse frequency, but not basal LH, when administered intra ARC in ovariectomised female rats ${ }^{120}$. Peptide 234 also delayed puberty in female rats ${ }^{116}$ which together with the effects on $\mathrm{GnRH}$ pulse frequency in pubertal and prepubertal monkeys confirms a role for KP in puberty which had been suggested by the failure to progress through puberty in patients with GPR 54 and KP mutations ${ }^{6,7}$.

Further studies with peptide 234 also demonstrated that KP is required for the elevation of $\mathrm{LH}$ when removing negative sex steroid feedback by orchidectomy of sheep and laboratory rodents ${ }^{109}$. The positive feedback of estrogen in the LH ovulatory surge in female rats was also shown directly to be KP dependent as peptide 234 inhibited this surge ${ }^{116}$, as was also demonstrated with KP antiserum ${ }^{115}$. 
Small molecule KP antagonists such as 15a (Figure 7) can penetrate the blood brain barrier. Similarly, peptide 271 , which has a penetratin sequence attached to convey brain penetration, was able to inhibit the LH stimulation by i.c.v. KP when it was administered systemically to rats ${ }^{116}$ and inhibit the LH surge in ewes ${ }^{121}$. A comparison of brain penetrant and non-penetrant KP antagonists on LH stimulation by systemic and i.c.v administered KP may shed light on the potential sites of action of KP on GnRH neuron cell body, axons and nerve terminals.

$\mathrm{KP}$ antagonists are powerful tools for demonstrating the physiological role of $\mathrm{KP}$ in $\mathrm{GnRH}$ neuron firing and $\mathrm{GnRH}$ pulsatility, in positive and negative feedback by gonadal steroids, in the LH surge of ovulation and in puberty. KP antagonists have also highlighted that $\mathrm{GnRH}$ secretion is not entirely dependent on $\mathrm{KP}$ as basal $\mathrm{GnRH}$ and $\mathrm{LH}$ were unaffected by $\mathrm{KP}$ antagonist in these studies. These studies demonstrate that KP antagonists may be effectively utilised to interrogate the role of $\mathrm{KP}$ in other physiological paradigms such as the effects of leptin, inhibin, activin, follistatin, nutrients and the dialogue of KP, NKB and dynorphin $\mathrm{A}$ in $\mathrm{GnRH} / \mathrm{LH}$ secretion.

\section{Potential therapeutic applications of KP analogues}

The effects of native KP-54 and KP-10 have been extensively studied in humans. KP-54 stimulated gonadotropins in healthy women and women with hypothalamic amenorrhea but long term treatment induced tachyphylaxis ${ }^{122}$ and administration to cycling women showed a greater gonadotropin response during the pre-ovulatory phase of the menstrual cycle ${ }^{90}$. Post-menopausal women had a greater response to $\mathrm{KP}-10$ than women in the follicular phase and women with progestogen implants while women on the combined contraceptive pill did not have a significant response ${ }^{123}$. Acute administration of KP-10 to normal men elicited robust stimulation of gonadotropins ${ }^{87,89}$ and continuous infusion of KP-10 for a day induced increasing gonadotropin secretion and increased pulse frequency with no tachphylaxis over this period ${ }^{89}$. This continuing response to KP-10 infusion continued for at least 36 hours (George, J et al. unpublished data). Continuous KP-10 infusion had similar effects in diabetic men and restored testosterone levels into the normal range ${ }^{123}$. These findings suggest that long acting formulations of KP. 10 or synthetic agonists (see below) might find utility in the induction of ovulation. On the other hand the 
findings by Takeda scientists that long term treatment with kisspeptin agonists can induce more rapid and profound inhibition of testosterone than the $\mathrm{GnRH}$ agonist, Leuprolide, in male rats suggests that agonists may also find utility in steroid hormone ablation to castration levels for treatment of prostate and breast cancers.

Since KP is a major regulator of $\mathrm{GnRH}$ but a degree of $\mathrm{GnRH}$ secretion appears to be KP independent, $\mathrm{KP}$ antagonists might be employed as partial inhibitors of gonadotropin and sex steroids. GnRH analogues have found extensive therapeutic applications in hormone-dependent diseases and in IVF. $\mathrm{GnRH}$ agonists induce gonadotrope desensitization while antagonists prevent receptor activation by endogenous $\mathrm{GnRH}$. Both treatments result in suppression of gonadotropin secretion with consequent reduction in circulating gonadal steroid hormones. In these treatments steroid hormones are lowered to castrate levels resulting in side effects such as hot flushes, reduced lean body mass, loss of libido and bone loss. The demonstration that KP antagonists reduce LH pulsatility ${ }^{109,120}$ and inhibit the ovulatory LH surge ${ }^{116}$, but do not appear to affect basal LH, suggests that they may find clinical utility in conditions where maximal suppression of sex steroids is contra-indicated. Examples are benign prostatic hyperplasia, endometriosis and uterine fibroids where lowering of gonadal steroids could improve the conditions without the side effects of reducing steroid hormones to castrate levels.

PCOS, which is characterised by increased LH pulse frequency and increased ratio to $\mathrm{FSH}$, is another potential target of KP therapy. Although unproven, lowering of $\mathrm{GnRH}$ pulse frequency by KP antagonists should maintain FSH (favored by low pulse frequency) while lowering $\mathrm{LH}$, as desired in PCOS. The reduction in LH pulse frequency by kisspeptin antagonists in animal studies and increase in pulse frequency by continuous kisspeptin in human studies $89,109,110,124$ supports the possibility of this therapeutic approach for PCOS. Furthermore, the putative effect of antagonist on increasing FSH/LH ratios would allow follicle development and estrogen production but inhibit ovulation, making KP antagonist administration an interesting possibility as a female contraceptive. KP antagonists may also find application in IVF to prevent premature luteinisation while maintaining basal LH, which may be of value in some women during superovulation ${ }^{125,126 .}$ 
In summary, the discovery of KP antagonists potentially provides a new avenue for investigating the role of KP in the normal physiology and pathophysiology of gonadotropin regulation. They also have potentially new therapeutic value for the treatment of hormone-dependent diseases without generating side effects of current therapeutics which induce total ablation of gonadal steroids.

\section{NKB analogues}

\section{Background}

NKB recently emerged as a novel neuropeptide with a crucial role in the neuroendocrine regulation of reproduction. In 2009, inactivating mutations in the human genes encoding NKB and its cognate receptor, TACR3/NK3R, were shown, like GPR54 mutations, to result in a failure to progress through puberty and in hypogonadotropic hypogonadism in adulthood ${ }^{9-11}$. In contrast, the original study of an inactivating mutation in the Tacr3 gene (encoding TACR3) in mice, did not observe reproductive impairment ${ }^{127}$. However, a subsequent study showed this model partially recapitulates the phenotype in humans ${ }^{128}$. Numerous studies on the role of NKB in laboratory rodents have been conducted which reveal apparently contradictory findings and a more complex role for the neuropeptide. These will not be reviewed here. Instead the reader is referred to a recent comprehensive review ${ }^{129}$. Other studies in monkeys ${ }^{130}$, goats ${ }^{131}$ and sheep ${ }^{132}$ show a clear stimulatory role for NKB in gonadotropin secretion; in keeping with the observations in humans of decreased LH in the absence of NKB signaling. The patients with inactivating mutations of genes encoding NKB or its receptor were characterized by very low LH but normal or near-normal circulating FSH levels ${ }^{9}$. This situation would be produced by a low GnRH pulse frequency ${ }^{133}$. In contrast, inactivating mutations in the KP receptor (GPR54) result in low levels of both $\mathrm{LH}$ and $\mathrm{FSH}^{6,7}$. Thus, it was suggested that a loss of $\mathrm{KP}$ signaling leads to a major loss of $\mathrm{GnRH}$ pulsatility whilst a loss of NKB signaling leads to low frequency GnRH pulsatility ${ }^{134}$.

KP neurons in the ARC have been shown to co-express NKB and dynorphin A (DYN) ${ }^{131,135-137}$ and have therefore been named KNDY neurons ${ }^{135}$. Since GnRH neurons express GPR54 but apparently not 
TACR3 ${ }^{132,137,138}$, while KNDY do express TACR3, it was further postulated that NKB secreted from KNDY neurons acts in an autocrine or paracrine manner to enhance KP secretion and that NKB actions were upstream of $\mathrm{KP}^{134}$. This notion was supported by the demonstration that continuous infusion of $\mathrm{KP}$ at a GPR54-saturating concentration in patients with NKB and TACR3 inactivating mutations restored LH pulsatility ${ }^{134}$. The conclusion that NKB operates upstream of KP in humans is in agreement with studies in monkeys ${ }^{130}$ and goats ${ }^{131}{ }^{138}$. The regulation of NKB by a number of physiological processes has recently been reviewed ${ }^{129}$.

The positioning of NKB actions upstream of KP raises the possibility that modulation of NKB signaling with agonists and antagonists will be more subtle than analogue modulation of KP signaling which in turn is more subtle than modulation of $\mathrm{GnRH}$ signaling. This being the case, there are distinct opportunities for the development and utilization of drugs which target the three levels of the neuroendocrine cascade with differential effects on gonadotropin and steroid hormones.

\section{NKB and peptide analogues}

NKB (neurokinin $\beta, \beta$-neurokinin, neuromedin K, neurokinin 3 ) is a decapeptide (Figure 8) cleaved from a prepro precursor protein. It is a member of the tachykinin family of peptides which are characterised by a common carboxyl-terminal motif: Phe-X-Gly-Leu-Met-NH . Receptor affinities of the different tachykinins are specified by variations in the amino terminal domain of the peptide. NKB was first identified in the 1980's as a substance P-related peptide in porcine spinal chord ${ }^{139}$.

NKB interacts with all three mammalian GPCR tachykinin receptors (TACR1, TACR2 and TACR3) but has highest selectivity for TACR3. This NKB selective tachykinin receptor was first identified through binding studies in mammalian CNS and functional studies using guinea pig illeum ${ }^{140-142}$, leading to the cloning of the human TACR3 in $1992^{143}$. 
There are several hundred patents and publications describing tachykinin analogues and their therapeutic utility. The majority of these have selectivity for TACR1 or TACR2 However, a number of analogues have been developed which are highly selective for TACR3. As the importance of NKB in the neuroendocrine control of reproduction is a relatively recent discovery, the therapeutic targets for TACR3 selective antagonists have generally been in the CNS field (e.g. schizophrenia, anxiety, pain, inflammation) and also in some pulmonary (e.g. chronic obstructive pulmonary disease) and gastrointestinal tract (e.g. irritable bowel syndrome) diseases. This, however, provides an opportunity to exploit these analogues in delineating the role of NKB in reproduction and as potential therapeutics in this area.

The first TACR3 selective peptide analogue agonist, senktide (selective neurokinin B receptor peptide), was developed by systematic methylation of the peptide bonds in a truncated version of the TACR1 selective tachykinin, substance P. Replacement of selected peptide bond hydrogens with methyl groups removed potential hydrogen bonding interactions and restricted conformation of the peptide which led to the identification of analogues with different receptor selectivity profiles. Senktide (Figure 8), in which $\mathrm{Phe}^{8}$ is methylated, was found to have very high specificity for TACR3 compared to NKB ${ }^{144}$. In addition, this modified peptide also had much higher metabolic stability than the native tachykinins, making it a useful experimental tool ${ }^{145}$. An analogue of NKB in which the $\mathrm{Val}^{7}$ has been replaced with mePhe in a similar way ([MePhe $\left.{ }^{7}\right] \mathrm{NKB}$, (Figure 8) also retains high affinity for the TACR3 and has improved selectivity for TACR3 over the other tachykinin receptors ${ }^{146}$. Replacing $\mathrm{Val}^{7}$ of $\mathrm{NKB}$ with Pro also improves selectivity for the TACR3 ${ }^{147}$.

Development and screening of a dipeptide library for binding affinity at the human TACR3 led to the identification of a lead dipeptide compound with low affinity (Boc-(S)Phe-(S)Phe- $\left.\mathrm{NH}_{2}\right)$. Modification and optimisation of this lead resulted in the development of the high affinity, TACR3 selective, 'peptoid' antagonists, PD157672 and subsequently PD161182 ${ }^{148}$. 
Several, non-peptide TACR3 selective antagonists have been developed. These fall into two main structural classes: dichlorophenylalkylpiperidines (e.g. osanetant) and quinolones (e.g. talnetant).

Osanetant (SR142801) (Figure 8) was developed by modification of a TACR2 receptor selective compound, saredudant, and was the first high-affinity non-peptide TACR3 selective antagonist to be described ${ }^{149-152}$. Modified analogues of osanetant, including SSR-146997, have since been developed 153,154

Differentially substituted 4-quinoline caboxyamides have also been identified as TACR3 selective antagonists which displayed similar potency but increased TACR3 selectivity compared to osanetant ${ }^{155}$. Modifications to optimise these initial compounds led to the identification of talnetant (SB-223412), an orally-active, potent and selective TACR3 antagonist ${ }^{156-158}$. Analogs of talnetant with increased bloodbrain barrier permeability, SB-222200 ${ }^{159}$ and GSK256471 ${ }^{160}$, or no blood-brain barrier permeability (SB335375) ${ }^{161}$ have since been described. Other talnetant-based TACR3 antagonists have also been developed including AZD2624 ${ }^{162}$ and a N'2-diphenylquinoline-4-carbohydrazide (Merck compound 8m) 163

One of the biggest problems with pre-clinical testing of these TACR3 antagonists is their species selectivity with compounds from both chemical classes displaying 10-100 fold higher affinity at the human TACR3 compared to the mouse or rat receptor, thus making their testing in relevant pre-clinical disease models difficult ${ }^{151,164}$.

\section{Potential therapeutic applications of NKB analogues}

Although TACR3 antagonists have not been clinically tested for reproductive effects, osanetant, talnetant and AZD2624, have been subject to several clinical trials assessing their effectiveness in treating CNS 
disorders (e.g. schizophrenia, anxiety and depression) and other non-CNS indications (e.g. IBS or overactive bladder). Although initial trials provided some promising data on the use of these compounds for the treatment of schizophrenia, subsequent trials have been inconclusive. As a result, clinical development of most of these TACR3 antagonists for the treatment of CNS disorders have been discontinued (see ${ }^{165}$ for a recent review).

The development of NKB agonists and antagonists have potential in therapeutic interventions in various dysfunctions of the reproductive system. As mentioned earlier, the upstream position of NKB suggests that analogues will have less complete effects than KP analogues which in turn will have less complete effects than $\mathrm{GnRH}$ analogues. Consequently, use of NKB antagonists, or desensitisation with agonists, will potentially be less effective than $\mathrm{KP}$ or $\mathrm{GnRH}$ analogues in lowering $\mathrm{LH}$ and have little effect on $\mathrm{FSH}$, as is evident in patients with deficiencies in NKB signaling. These analogues are therefore unlikely to be of value in treating hormone-dependent cancers, such as prostatic cancer, in which lowering of sex steroids to castration levels is a prerequisite for efficacy; as accomplished with $\mathrm{GnRH}$ analogues. However, this property may be valuable in treatment of hormone-dependent diseases, such as endometriosis and benign prostatic hyperplasia, which require partial inhibition of sex steroids and the avoidance of side effects such as bone loss, loss of libido and hot flushes which are characteristic of GnRH analogue treatment.

In addition, in conditions of decreased LH production and near normal FSH secretion (i.e. due to low GnRH pulse frequency) such as hypothalamic amenorrhea or delayed puberty ${ }^{166}$, restoration of LH and normal reproductive function may potentially be achieved by treatment with NKB (or KP) agonists. In conditions characterized by high LH pulse amplitude and frequency, such as PCOS ${ }^{167}$, NKB antagonists may be effective in lowering $\mathrm{LH}$ without affecting $\mathrm{FSH}$, thus restoring the normal $\mathrm{LH} / \mathrm{FSH}$ ratio. NKB antagonists appear to also have potential in novel female contraception as disruption of NKB signaling maintains $\mathrm{FSH}$ but decreases $\mathrm{LH}$ and therefore would potentially prevent ovulation. Like KP, NKB agonists may also find utility in a more gentle stimulation of gonadotropins in assisted reproduction technologies. 
A potential limitation in the therapeutic use of NKB agonists is tachyphylaxis, which has been reported in monkeys ${ }^{130}$. However, this may be an issue of time and dose, as although tachyphylaxis has also been observed in long-term administration of KP-54 to women with hypothalamic amenorrhea ${ }^{122}$ and in juvenile ${ }^{168}$ and adult ${ }^{169}$ monkeys, it was not observed in men receiving continuous infusion of KP-10 at near maximal LH stimulating levels over $22 \mathrm{hrs} .{ }^{89}$.

\section{Conclusions}

Reproductive hormones play an important role at all stages of life from gamete production and fertilization, through puberty and adulthood to senescence. The hormone cascade of brain neuroendocrine peptides, gonadotropins and steroid hormones are all targets for the development of analogues for intervention in normal physiological and pathophysiological processes. Novel orally-active $\mathrm{GnRH}$ analogues and the arrival of novel neuroendocrine analogues of KP and NKB increases therapeutic options, and their more proximal position in the cascade holds promise for more subtle interventions.

\section{Acknowledgements}

We acknowledge support from the Medical Research Council (South Africa), the National Research Foundation, the University of Pretoria and the University of Cape Town. CLN is a Claude Leon Foundation Postdoctoral Research Fellow. 


\section{References}

1. Fink, G. in The physiology of reproduction (eds Knobil, E. \& Neill, J.) 1349-1377 (Raven Press, New York, 1988).

2. Seeburg, P. H., Mason, A. J., Stewart, T. A. \& Nikolics, K. The mammalian GnRH gene and its pivotal role in reproduction. Recent Prog. Horm. Res. 43, 69-98 (1987).

3. Millar, R. P. et al. Gonadotropin-releasing hormone receptors. Endocr. Rev. 25, 235-75 (2004).

4. Millar, R. P. GnRHs and GnRH receptors Anim. Reprod. Sci. 88, 5 - 28 (2005).

5. Navarro, V. M. \& Tena-Sempere, M. Neuroendocrine control by kisspeptins: role in metabolic regulation of fertility. Nat. Rev. Endocrinol. 8, 40-53 (2012).

6. de Roux, N. et al. Hypogonadotropic hypogonadism due to loss of function of the KiSS1-derived peptide receptor GPR54. Proc. Natl. Acad. Sci. U. S. A. 100, 10972-6 (2003).

7. Seminara, S. B. et al. The GPR54 gene as a regulator of puberty. N. Engl. J. Med. 349, 1614-27 (2003).

8. Topaloglu, A. K. et al. Inactivating KISS1 mutation and hypogonadotropic hypogonadism. N. Engl. J. Med. 366, 629-35 (2012).

9. Topaloglu, A. K. et al. TAC3 and TACR3 mutations in familial hypogonadotropic hypogonadism reveal a key role for Neurokinin B in the central control of reproduction. Nat. Genet. 41, 354-358 (2009).

10. Gianetti, E. et al. TAC3/TACR3 mutations reveal preferential activation of gonadotropin-releasing hormone release by neurokinin B in neonatal life followed by reversal in adulthood. J. Clin. Endocrinol. Metab. 95, 2857-2867 (2010).

11. Young, J. et al. TAC3 and TACR3 defects cause hypothalamic congenital hypogonadotropic hypogonadism in humans. J. Clin. Endocrinol. Metab. 95, 2287-2295 (2010).

12. Terasawa, E. \& Fernandez, D. L. Neurobiological mechanisms of the onset of puberty in primates. Endocr. Rev. 22, 111-151 (2001).

13. Roa, J. \& Herbison, A. E. Direct regulation of $\mathrm{GnRH}$ neuron excitability by arcuate nucleus POMC and NPY neuron neuropeptides in female mice. Endocrinology 153, 5587-5599 (2012).

14. Matsuo, H., Baba, Y., Nair, R. M., Arimura, A. \& Schally, A. V. Structure of the porcine LH- and FSHreleasing hormone. I. The proposed amino acid sequence. Biochem. Biophys. Res. Commun. 43, 13341339 (1971).

15. Baba, Y., Matsuo, H. \& Schally, A. V. Structure of the porcine LH- and FSH-releasing hormone. II. Confirmation of the proposed structure by conventional sequential analyses Biochem. Biophys. Res. Commun. 44, 459 -463 (1971).

16. Schally, A. V. et al. Isolation and properties of the FSH and LH-releasing hormone. Biochem. Biophys. Res. Commun. 43, 393-399 (1971).

17. King, J. A. \& Millar, R. P. Heterogeneity of vertebrate luteinizing hormone-releasing hormone. Science 206, 67-69 (1979). 
18. King, J. A. \& Millar, R. P. Structure of chicken hypothalamic luteinizing hormone-releasing hormone. II. Isolation and characterization. J. Biol. Chem. 257, 10729 (1982).

19. King, J. A. \& Millar, R. P. Structure of chicken hypothalamic luteinizing hormone-releasing hormone.

I. Structural determination on partially purified material. J. Biol. Chem. 257, 10722 (1982).

20. Adams, B. A. Six Novel Gonadotropin-Releasing Hormones Are Encoded as Triplets on Each of Two Genes in the Protochordate, Ciona intestinalis Endocrinology 144, 1907 -1919 (2003).

21. Jimenez-Linan, M., Rubin, B. S. \& King, J. C. Examination of guinea pig luteinizing hormonereleasing hormone gene reveals a unique decapeptide and existence of two transcripts in the brain. Endocrinology 138, 4123-4130 (1997).

22. King, J. A. \& Millar, R. P. Evolution of gonadotropin-releasing hormones Trends in Endocrinology \& Metabolism 3, 339 -346 (1992).

23. King, J. A. \& Millar, R. P. Evolutionary aspects of gonadotropin-releasing hormone and its receptor. Cell. Mol. Neurobiol. 15, 5-23 (1995).

24. King, J. A. \& Millar, R. P. in GnRH Neurones: Gene to Behavior.(eds Parhar, I. S. \& Sakuma, Y.) 5177 (Brain Shuppan, Tokyo, 1997).

25. Millar, R. P., King, J. A., Davidson, J. S. \& Milton, R. C. Gonadotrophin-releasing hormone--diversity of functions and clinical applications. S. Afr. Med. J. 72, 748-55 (1987).

26. Millar, R. \& King, J. Evolution of Gonadotropin-Releasing Hormone: Multiple Usage of a Peptide. Physiology 3, 49-53 (1988).

27. Millar, R. P. et al. Plasticity in the structural and functional evolution of GnRH: a peptide for all seasons. (XIII International Congress of Comparative Endocrinology , 1997).

28. Okubo, K., Suetake, H., Usami, T. \& Aida, K. Molecular Cloning and Tissue-Specific Expression of a Gonadotropin-Releasing Hormone Receptor in the Japanese Eel Gen. Comp. Endocrinol. 119, 181-192 (2000).

29. Okubo, K., Amano, M., Yoshiura, Y., Suetake, H. \& Aida, K. A novel form of gonadotropin-releasing hormone in the medaka, Oryzias latipes. Biochem. Biophys. Res. Commun. 276, 298-303 (2000).

30. Sherwood, N. M. \& Lovejoy, D. A. The origin of the mammalian form of $\mathrm{GnRH}$ in primitive fishes Fish Physiol. Biochem. 7, 85 -93 (1989).

31. Sherwood, N. M., Lovejoy, D. A. \& Coe, I. R. Origin of Mammalian Gonadotropin-Releasing Hormones Endocr. Rev. 14, 241-254 (1993).

32. Yoo, M. S. et al. Molecular cloning, distribution and pharmacological characterization of a novel gonadotropin-releasing hormone (Trp8] GnRH) in frog brain. Mol. Cell. Endocrinol. 164, 197-204 (2000).

33. Roch, G. J., Busby, E. R. \& Sherwood, N. M. Evolution of GnRH: diving deeper. Gen. Comp. Endocrinol. 171, 1-16 (2011).

34. Sherwood, N. The GnRH family of peptides. Trends Neurosci. 10, 129-132 (1987).

35. Flanagan, C. A. et al. Glutamate 301 of the mouse gonadotropin-releasing hormone receptor confers specificity for arginine 8 of mammalian gonadotropin-releasing hormone. J. Biol. Chem. 269, 22636-41 (1994). 
36. Barran, P. E. et al. Evolution of constrained gonadotropin-releasing hormone ligand conformation and receptor selectivity. J. Biol. Chem. 280, 38569-75 (2005).

37. Pfleger, K. D., Bogerd, J. \& Millar, R. P. Conformational constraint of mammalian, chicken, and salmon GnRHs, but not GnRH II, enhances binding at mammalian and nonmammalian receptors: evidence for preconfiguration of GnRH II. Mol. Endocrinol. 16, 2155-62 (2002).

38. Karten, M. J. \& Rivier, J. E. Gonadotropin-Releasing Hormone Analog Design. Structure-Function Studies Toward the Development of Agonists and Antagonists: Rationale and Perspective Endocr. Rev. 7, 44 -66 (1986).

39. Sealfon, S. C., Weinstein, H. \& Millar, R. P. Molecular Mechanisms of Ligand Interaction with the Gonadotropin-Releasing Hormone Receptor Endocr. Rev. 18, 180 -205 (1997).

40. Heitman, L. H. \& ljzerman, A. P. G protein-coupled receptors of the hypothalamic-pituitary-gonadal axis: a case for Gnrh, LH, FSH, and GPR54 receptor ligands. Med. Res. Rev. 28, 975-1011 (2008).

41. Betz, S. F., Reinhart, G. J., Lio, F. M., Chen, C. \& Struthers, R. S. Overlapping, nonidentical binding sites of different classes of nonpeptide antagonists for the human gonadotropin-releasing hormone receptor. J. Med. Chem. 49, 637-647 (2006).

42. Cui, J. et al. Identification of Phe313 of the gonadotropin-releasing hormone $(\mathrm{GnRH})$ receptor as a site critical for the binding of nonpeptide GnRH antagonists. Mol. Endocrinol. 14, 671-681 (2000).

43. Chen, C. et al. Discovery of sodium R-(+)-4-\{2-[5-(2-fluoro-3-methoxyphenyl)-3-(2-fluoro-6[trifluoromethyl]benzyl)-4 -methyl-2,6-dioxo-3,6-dihydro-2H-pyrimidin-1-yl]-1-phenylethylamino\}butyrate (elagolix), a potent and orally available nonpeptide antagonist of the human gonadotropin-releasing hormone receptor. J. Med. Chem. 51, 7478-7485 (2008).

44. Miwa, K. et al. Discovery of 1-\{4-[1-(2,6-difluorobenzyl)-5-[(dimethylamino)methyl]-3-(6methoxypyridazin-3-yl )-2,4-dioxo-1,2,3,4-tetrahydrothieno[2,3-d]pyrimidin-6-yl]phenyl\}-3-methoxyurea (TAK-385) as a potent, orally active, non-peptide antagonist of the human gonadotropin-releasing hormone receptor. J. Med. Chem. 54, 4998-5012 (2011).

45. Struthers, R. S. et al. Suppression of gonadotropins and estradiol in premenopausal women by oral administration of the nonpeptide gonadotropin-releasing hormone antagonist elagolix. J. Clin.

Endocrinol. Metab. 94, 545-551 (2009).

46. Finch, A. R., Sedgley, K. R., Caunt, C. J. \& McArdle, C. A. Plasma membrane expression of GnRH receptors: regulation by antagonists in breast, prostate, and gonadotrope cell lines. J. Endocrinol. 196, 353-367 (2008).

47. Conn, P. M. \& Ulloa-Aguirre, A. Pharmacological chaperones for misfolded gonadotropin-releasing hormone receptors. Adv. Pharmacol. 62, 109-141 (2011).

48. Conn, P. M. \& Ulloa-Aguirre, A. Trafficking of G-protein-coupled receptors to the plasma membrane: insights for pharmacoperone drugs. Trends Endocrinol. Metab. 21, 190-197 (2010).

49. Tsutsumi, M. Cloning and functional expression of a mouse gonadotropin-releasing hormone receptor Molecular Endocrinology 6, 1163-1169 (1992).

50. Pawson, A. J. et al. Mammalian type I gonadotropin-releasing hormone receptors undergo slow, constitutive, agonist-independent internalization. Endocrinology 149, 1415-22 (2008).

51. Lahlou, N. et al. Gonadotropin and alpha-subunit secretion during long term pituitary suppression by D-Trp6-luteinizing hormone-releasing hormone microcapsules as treatment of precocious puberty. $J$. Clin. Endocrinol. Metab. 65, 946-953 (1987). 
52. Millar, R. P., Pawson, A. J., Morgan, K., Rissman, E. F. \& Lu, Z. L. Diversity of actions of GnRHs mediated by ligand-induced selective signaling Front. Neuroendocrinol. 29, 17-35 (2008).

53. Casper, R. F. Clinical uses of gonadotropin-releasing hormone analogues. CMAJ 144, 153-158 (1991).

54. Conn, P. M. \& Crowley, W. F.,Jr. Gonadotropin-releasing hormone and its analogues. N. Engl. J. Med. 324, 93-103 (1991).

55. Barbieri, R. L. Clinical applications of $\mathrm{GnRH}$ and its analogues Trends in Endocrinology \& Metabolism 3, 30 -34 (1992).

56. Moghissi, K. S. Clinical applications of gonadotropin-releasing hormones in reproductive disorders. Endocrinol. Metab. Clin. North Am. 21, 125-140 (1992).

57. Filicori, M. Gonadotrophin-Releasing Hormone Agonists Drugs 48, 41-58 (1994).

58. Emons, G. \& Schally, A. V. The use of luteinizing hormone releasing hormone agonists and antagonists in gynaecological cancers. Hum. Reprod. 9, 1364-1379 (1994).

59. Rivier, J. E. et al. New effective gonadotropin releasing hormone antagonists with minimal potency for histamine release in vitro. J. Med. Chem. 29, 1846-1851 (1986).

60. Schlegel, P. N. et al. Effective long-term androgen suppression in men with prostate cancer using a hydrogel implant with the $\mathrm{GnRH}$ agonist histrelin. Urology 58, 578-582 (2001).

61. Barbieri, R. L. Hormone treatment of endometriosis: the estrogen threshold hypothesis. Am. J. Obstet. Gynecol. 166, 740-745 (1992).

62. Surrey, E. S. Add-back therapy and gonadotropin-releasing hormone agonists in the treatment of patients with endometriosis: can a consensus be reached? Add-Back Consensus Working Group. Fertil. Steril. 71, 420-424 (1999).

63. Franke, H. R., van de Weijer, P. H., Pennings, T. M. \& van der Mooren, M. J. Gonadotropin-releasing hormone agonist plus "add-back" hormone replacement therapy for treatment of endometriosis: a prospective, randomized, placebo-controlled, double-blind trial. Fertil. Steril. 74, 534-539 (2000).

64. Ratcliffe, K. E., Fraser, H. M., Sellar, R., Rivier, J. \& Millar, R. P. Bifunctional gonadotropin-releasing hormone antagonist-progesterone analogs with increased efficacy and duration of action. Endocrinology $147,571-9$ (2006).

65. Akaza, $\mathrm{H}$. Future prospects for luteinizing hormone-releasing hormone analogues in prostate cancer treatment. Pharmacology 85, 110-120 (2010).

66. Porter, R. N., Smith, W., Craft, I. L., Abdulwahid, N. A. \& Jacobs, H. S. Induction of ovulation for invitro fertilisation using buserelin and gonadotropins. Lancet 2, 1284-1285 (1984).

67. Kiesel, L. A., Rody, A., Greb, R. R. \& Szilagyi, A. Clinical use of GnRH analogues. Clin. Endocrinol. $56,677-687$ (2002).

68. Franks, S. Polycystic ovary syndrome. N. Engl. J. Med. 333, 853-861 (1995).

69. Lethaby, A., Vollenhoven, B. \& Sowter, M. Pre-operative GnRH analogue therapy before hysterectomy or myomectomy for uterine fibroids. Cochrane Database Syst. Rev. (2), CD000547 (2001).

70. Colacurci, N. et al. The use of $\mathrm{GnRH}$ agonists depot for the treatment of dysfunctional uterine bleeding. Acta Eur. Fertil. 22, 229-231 (1991). 
71. Klijn, J. G. M. et al. Combined Treatment With Buserelin and Tamoxifen in Premenopausal Metastatic Breast Cancer: a Randomized Study. Journal of the National Cancer Institute 92, 903-911 (2000).

72. Wang, P. H., Chao, H. T. \& Lee, W. L. Use of a long-acting gonadotropin-releasing hormone agonist for treatment of steroid cell tumors of the ovary. Fertil. Steril. 69, 353-355 (1998).

73. Covens, A. et al. A phase II study of leuprolide in advanced/recurrent endometrial cancer. Gynecol. Oncol. 64, 126-129 (1997).

74. Dockray, G. J. The expanding family of -RFamide peptides and their effects on feeding behaviour. Exp. Physiol. 89, 229-235 (2004).

75. Ohtaki, T. et al. Metastasis suppressor gene KiSS-1 encodes peptide ligand of a G-protein-coupled receptor. Nature 411, 613-7 (2001).

76. Roseweir, A. K. \& Millar, R. P. The role of kisspeptin in the control of gonadotrophin secretion. Hum. Reprod. Update 15, 203-212 (2009).

77. Kotani, M. et al. The metastasis suppressor gene KiSS-1 encodes kisspeptins, the natural ligands of the orphan G protein-coupled receptor GPR54. J. Biol. Chem. 276, 34631-6 (2001).

78. Mikkelsen, J. D., Bentsen, A. H., Ansel, L., Simonneaux, V. \& Juul, A. Comparison of the effects of peripherally administered kisspeptins. Regul. Pept. 152, 95-100 (2009).

79. Tovar, S. et al. Effects of single or repeated intravenous administration of kisspeptin upon dynamic LH secretion in conscious male rats. Endocrinology 147, 2696-2704 (2006).

80. Thompson, E. L. et al. Central and peripheral administration of kisspeptin-10 stimulates the hypothalamic-pituitary-gonadal axis. J. Neuroendocrinol. 16, 850-858 (2004).

81. Navarro, V. M. et al. Effects of KiSS-1 peptide, the natural ligand of GPR54, on follicle-stimulating hormone secretion in the rat. Endocrinology 146, 1689-1697 (2005).

82. Navarro, V. M. et al. Characterization of the potent luteinizing hormone-releasing activity of KiSS-1 peptide, the natural ligand of GPR54. Endocrinology 146, 156-163 (2005).

83. Plant, T. M., Ramaswamy, S. \& Dipietro, M. J. Repetitive activation of hypothalamic G proteincoupled receptor 54 with intravenous pulses of kisspeptin in the juvenile monkey (Macaca mulatta) elicits a sustained train of gonadotropin-releasing hormone discharges. Endocrinology 147, 1007-1013 (2006).

84. Shahab, M. et al. Increased hypothalamic GPR54 signaling: a potential mechanism for initiation of puberty in primates. Proc. Natl. Acad. Sci. U. S. A. 102, 2129-2134 (2005).

85. Irwig, M. S. et al. Kisspeptin activation of gonadotropin releasing hormone neurons and regulation of KiSS-1 mRNA in the male rat. Neuroendocrinology 80, 264-272 (2004).

86. Messager, S. et al. Kisspeptin directly stimulates gonadotropin-releasing hormone release via $\mathrm{G}$ protein-coupled receptor 54. Proc. Natl. Acad. Sci. U. S. A. 102, 1761-1766 (2005).

87. Dhillo, W. S. et al. Kisspeptin-54 stimulates the hypothalamic-pituitary gonadal axis in human males. J. Clin. Endocrinol. Metab. 90, 6609-6615 (2005).

88. George, J. T., Millar, R. P. \& Anderson, R. A. Hypothesis: kisspeptin mediates male hypogonadism in obesity and type 2 diabetes. Neuroendocrinology 91, 302-307 (2010). 
89. George, J. T. et al. Kisspeptin-10 is a potent stimulator of LH and increases pulse frequency in men. J. Clin. Endocrinol. Metab. 96, E1228-36 (2011).

90. Dhillo, W. S. et al. Kisspeptin-54 stimulates gonadotropin release most potently during the preovulatory phase of the menstrual cycle in women. J. Clin. Endocrinol. Metab. 92, 3958-3966 (2007).

91. Estrada, K. M., Clay, C. M., Pompolo, S., Smith, J. T. \& Clarke, I. J. Elevated KiSS-1 expression in the arcuate nucleus prior to the cyclic preovulatory gonadotrophin-releasing hormone/lutenising hormone surge in the ewe suggests a stimulatory role for kisspeptin in oestrogen-positive feedback. $J$.

Neuroendocrinol. 18, 806-9 (2006).

92. Franceschini, I. et al. Kisspeptin immunoreactive cells of the ovine preoptic area and arcuate nucleus co-express estrogen receptor alpha. Neurosci. Lett. 401, 225-30 (2006).

93. Smith, J. T., Cunningham, M. J., Rissman, E. F., Clifton, D. K. \& Steiner, R. A. Regulation of Kiss1 gene expression in the brain of the female mouse. Endocrinology 146, 3686-92 (2005).

94. Smith, J. T. et al. Differential regulation of KiSS-1 mRNA expression by sex steroids in the brain of the male mouse. Endocrinology 146, 2976-84 (2005).

95. Adachi, S. et al. Involvement of anteroventral periventricular metastin/kisspeptin neurons in estrogen positive feedback action on luteinizing hormone release in female rats. J Reprod Dev 53, 367-78 (2007).

96. Clarkson, J. \& Herbison, A. E. Postnatal development of kisspeptin neurons in mouse hypothalamus; sexual dimorphism and projections to gonadotropin-releasing hormone neurons. Endocrinology 147, 5817-5825 (2006).

97. Pompolo, S., Pereira, A., Estrada, K. M. \& Clarke, I. J. Colocalization of kisspeptin and gonadotropinreleasing hormone in the ovine brain. Endocrinology 147, 804-10 (2006).

98. Ramaswamy, S., Guerriero, K. A., Gibbs, R. B. \& Plant, T. M. Structural interactions between kisspeptin and $\mathrm{GnRH}$ neurons in the mediobasal hypothalamus of the male rhesus monkey (Macaca mulatta) as revealed by double immunofluorescence and confocal microscopy. Endocrinology 149, 4387-4395 (2008).

99. Tena-Sempere, M. KiSS-1 and reproduction: focus on its role in the metabolic regulation of fertility. Neuroendocrinology 83, 275-281 (2006).

100. Roa, J., Aguilar, E., Dieguez, C., Pinilla, L. \& Tena-Sempere, M. New frontiers in kisspeptin/GPR54 physiology as fundamental gatekeepers of reproductive function. Front. Neuroendocrinol. 29, 48-69 (2008).

101. Smith, J. T., Acohido, B. V., Clifton, D. K. \& Steiner, R. A. KiSS-1 neurones are direct targets for leptin in the ob/ob mouse. J. Neuroendocrinol. 18, 298-303 (2006).

102. Donato, J.,Jr et al. Leptin's effect on puberty in mice is relayed by the ventral premammillary nucleus and does not require signaling in Kiss1 neurons. J. Clin. Invest. 121, 355-368 (2011).

103. Castellano, J. M. et al. Alterations in hypothalamic KiSS-1 system in experimental diabetes: early changes and functional consequences. Endocrinology 150, 784-794 (2009).

104. Castellano, J. M. et al. Changes in hypothalamic KiSS-1 system and restoration of pubertal activation of the reproductive axis by kisspeptin in undernutrition. Endocrinology 146, 3917-3925 (2005).

105. Pinilla, L., Aguilar, E., Dieguez, C., Millar, R. P. \& Tena-Sempere, M. Kisspeptins and reproduction: physiological roles and regulatory mechanisms. Physiol. Rev. 92, 1235-1316 (2012). 
106. Oakley, A. E., Clifton, D. K. \& Steiner, R. A. Kisspeptin signaling in the brain. Endocr. Rev. 30, 713743 (2009).

107. Orsini, M. J. et al. Metastin (KiSS-1) mimetics identified from peptide structure-activity relationshipderived pharmacophores and directed small molecule database screening. J. Med. Chem. 50, 462-71 (2007).

108. Gutierrez-Pascual, E. et al. In vivo and in vitro structure-activity relationships and structural conformation of Kisspeptin-10-related peptides. Mol. Pharmacol. 76, 58 (2009).

109. Roseweir, A. K. et al. Discovery of potent kisspeptin antagonists delineate physiological mechanisms of gonadotropin regulation. J. Neurosci. 29, 3920-3929 (2009).

110. Millar, R. P. et al. Kisspeptin antagonists: unraveling the role of kisspeptin in reproductive physiology. Brain Res. 1364, 81 (2010).

111. Asami, T. \& Nishizawa, N. Metastin derivatives and use thereof. Patent no. US 7,960,348 B2. (2011).

112. Kitada, C., Asami, T. \& Nishizawa, N. Metastin derivatives and use thereof. Patent No. 7,625,869. (2009).

113. Matsui, H. et al. Chronic administration of the metastin/kisspeptin analog KISS1-305 or the investigational agent TAK-448 suppresses hypothalamic pituitary gonadal function and depletes plasma testosterone in adult male rats. Endocrinology 153, 5297-5308 (2012).

114. Liu, X. et al. Frequency-dependent recruitment of fast amino acid and slow neuropeptide neurotransmitter release controls gonadotropin-releasing hormone neuron excitability. J. Neurosci. 31, 2421-2430 (2011).

115. Kinoshita, M. et al. Involvement of central metastin in the regulation of preovulatory luteinizing hormone surge and estrous cyclicity in female rats. Endocrinology 146, 4431-6 (2005).

116. Pineda, R. et al. Critical roles of kisspeptins in female puberty and preovulatory gonadotropin surges as revealed by a novel antagonist. Endocrinology 151, 722-730 (2010).

117. Kobayashi, T. et al. Synthesis and structure-activity relationships of 2-acylamino-4,6diphenylpyridine derivatives as novel antagonists of GPR54. Bioorg. Med. Chem. 18, 3841-59 (2010).

118. Kobayashi, T. et al. 2-acylamino-4,6-diphenylpyridine derivatives as novel GPR54 antagonists with good brain exposure and in vivo efficacy for plasma LH level in male rats. Bioorg. Med. Chem. 18, 515771 (2010).

119. Guerriero, K. A., Keen, K. L., Millar, R. P. \& Terasawa, E. Developmental changes in GnRH release in response to kisspeptin agonist and antagonist in female rhesus monkeys (Macaca mulatta):

implication for the mechanism of puberty. Endocrinology 153, 825-836 (2012).

120. Li, X. F. et al. Kisspeptin signalling in the hypothalamic arcuate nucleus regulates $\mathrm{GnRH}$ pulse generator frequency in the rat. PLoS One 4, e8334 (2009).

121. Smith, J. T. et al. Kisspeptin is essential for the full preovulatory LH surge and stimulates $\mathrm{GnRH}$ release from the isolated ovine median eminence. Endocrinology 152, 1001-12 (2011).

122. Jayasena, C. N. et al. Subcutaneous injection of kisspeptin-54 acutely stimulates gonadotropin secretion in women with hypothalamic amenorrhea, but chronic administration causes tachyphylaxis. $J$. Clin. Endocrinol. Metab. 94, 4315-4323 (2009). 
123. George, J. T., Anderson, R. A. \& Millar, R. P. Kisspeptin-10 stimulation of gonadotrophin secretion in women is modulated by sex steroid feedback. Hum. Reprod. (2012).

124. George, J. T., Veldhuis, J. D., Tena-Sempere, M., Millar, R. P. \& Anderson, R. A. Exploring the pathophysiology of hypogonadism in men with type 2 diabetes: Kisspeptin-10 stimulates serum testosterone and LH secretion in men with type 2 diabetes and mild biochemical hypogonadism. Clin. Endocrinol. (Oxf) (2012).

125. Durnerin, C. I. et al. Effects of recombinant LH treatment on folliculogenesis and responsiveness to FSH stimulation. Hum. Reprod. 23, 421-6 (2008).

126. Drakakis, P. et al. 2770481; Early hCG addition to rFSH for ovarian stimulation in IVF provides better results and the cDNA copies of the hCG receptor may be an indicator of successful stimulation. Reprod Biol Endocrinol 7, 110 (2009).

127. Kung, T. T. et al. Tachykinin NK3-receptor deficiency does not inhibit pulmonary eosinophilia in allergic mice. Pharmacol. Res. 50, 611-615 (2004).

128. Yang, J. J., Caligioni, C. S., Chan, Y. M. \& Seminara, S. B. Uncovering novel reproductive defects in neurokinin B receptor null mice: closing the gap between mice and men. Endocrinology 153, 14981508 (2012).

129. Navarro, V. M. New insights into the control of pulsatile $\mathrm{GnRH}$ release: the role of Kiss $1 /$ neurokinin B neurons. Front. Endocrinol. 3, 48 (2012).

130. Ramaswamy, S., Seminara, S. B. \& Plant, T. M. Evidence from the agonadal juvenile male rhesus monkey (Macaca mulatta) for the view that the action of neurokinin B to trigger gonadotropin-releasing hormone release is upstream from the kisspeptin receptor. Neuroendocrinology 94, 237-245 (2011).

131. Wakabayashi, Y. et al. Neurokinin B and dynorphin A in kisspeptin neurons of the arcuate nucleus participate in generation of periodic oscillation of neural activity driving pulsatile gonadotropin-releasing hormone secretion in the goat. J. Neurosci. 30, 3124-3132 (2010).

132. Billings, $H$. J. et al. Neurokinin $B$ acts via the neurokinin-3 receptor in the retrochiasmatic area to stimulate luteinizing hormone secretion in sheep. Endocrinology 151, 3836-3846 (2010).

133. Dalkin, A. C., Haisenleder, D. J., Ortolano, G. A., Ellis, T. R. \& Marshall, J. C. The frequency of gonadotropin-releasing-hormone stimulation differentially regulates gonadotropin subunit messenger ribonucleic acid expression. Endocrinology 125, 917-24 (1989).

134. Young, J. et al. Kisspeptin Restores Pulsatile LH Secretion in Patients with Neurokinin B Signaling Deficiencies: Physiological, Pathophysiological and Therapeutic Implications. Neuroendocrinology In Press (2012).

135. Lehman, M. N., Coolen, L. M. \& Goodman, R. L. Minireview: kisspeptin/neurokinin B/dynorphin (KNDy) cells of the arcuate nucleus: a central node in the control of gonadotropin-releasing hormone secretion. Endocrinology 151, 3479-3489 (2010).

136. Goodman, R. L. et al. Kisspeptin neurons in the arcuate nucleus of the ewe express both dynorphin A and neurokinin B. Endocrinology 148, 5752-60 (2007).

137. Navarro, V. M. et al. Regulation of NKB pathways and their roles in the control of Kiss1 neurons in the arcuate nucleus of the male mouse. Endocrinology 152, 4265-4275 (2011).

138. Amstalden, M. et al. Neurokinin 3 receptor immunoreactivity in the septal region, preoptic area and hypothalamus of the female sheep: colocalisation in neurokinin B cells of the arcuate nucleus but not in gonadotrophin-releasing hormone neurones. J. Neuroendocrinol. 22, 1-12 (2010). 
139. Kangawa, K., Minamino, N., Fukuda, A. \& Matsuo, H. Neuromedin K: a novel mammalian tachykinin identified in porcine spinal cord. Biochem. Biophys. Res. Commun. 114, 533-540 (1983).

140. Laufer, R. et al. Neurokinin B is a preferred agonist for a neuronal substance $P$ receptor and its action is antagonized by enkephalin. Proc. Natl. Acad. Sci. U. S. A. 82, 7444-7448 (1985).

141. Buck, S. H., Burcher, E., Shults, C. W., Lovenberg, W. \& O'Donohue, T. L. Novel pharmacology of substance K-binding sites: a third type of tachykinin receptor. Science 226, 987-989 (1984).

142. Torrens, Y. et al. Neuromedin K, a tool to further distinguish two central tachykinin binding sites. Eur. J. Pharmacol. 102, 381-382 (1984).

143. Buell, G. et al. Molecular characterisation, expression and localisation of human neurokinin-3 receptor. FEBS Lett. 299, 90-95 (1992).

144. Wormser, U. et al. Highly selective agonists for substance P receptor subtypes. EMBO J. 5, 28052808 (1986).

145. Laufer, R., Gilon, C., Chorev, M. \& Selinger, Z. Characterization of a neurokinin B receptor site in rat brain using a highly selective radioligand. J. Biol. Chem. 261, 10257-10263 (1986).

146. Drapeau, G. et al. Selective agonists for substance P and neurokinin receptors. Neuropeptides 10, 43-54 (1987).

147. Lavielle, S. et al. Selective agonists of tachykinin binding sites. Fundam. Clin. Pharmacol. 4, 257268 (1990).

148. Boden, P. et al. Use of a dipeptide chemical library in the development of non-peptide tachykinin NK3 receptor selective antagonists. J. Med. Chem. 39, 1664-1675 (1996).

149. Emonds-Alt, X. et al. SR 142801, the first potent non-peptide antagonist of the tachykinin NK3 receptor. Life Sci. 56, PL27-32 (1995).

150. Oury-Donat, F. et al. Functional characterization of the nonpeptide neurokinin3 (NK3) receptor antagonist, SR142801 on the human NK3 receptor expressed in Chinese hamster ovary cells. J. Pharmacol. Exp. Ther. 274, 148-154 (1995).

151. Chung, F. Z. et al. Two classes of structurally different antagonists display similar species preference for the human tachykinin neurokinin3 receptor. Mol. Pharmacol. 48, 711-716 (1995).

152. Nguyen-Le, X. K. et al. Pharmacological characterization of SR 142801: a new non-peptide antagonist of the neurokinin NK-3 receptor. Pharmacology 52, 283-291 (1996).

153. Emonds-Alt, X. et al. Biochemical and pharmacological activities of SSR 146977, a new potent nonpeptide tachykinin NK3 receptor antagonist. Can. J. Physiol. Pharmacol. 80, 482-488 (2002).

154. Harrison, T. et al. High affinity, selective neurokinin 2 and neurokinin 3 receptor antagonists from a common structural template. Bioorg. Med. Chem. Lett. 8, 1343-1348 (1998).

155. Giardina, G. A. et al. 2-Phenyl-4-quinolinecarboxamides: a novel class of potent and selective nonpeptide competitive antagonists for the human neurokinin-3 receptor. J. Med. Chem. 39, 2281-2284 (1996).

156. Giardina, G. A. et al. Discovery of a novel class of selective non-peptide antagonists for the human neurokinin-3 receptor. 1. Identification of the 4-quinolinecarboxamide framework. J. Med. Chem. 40, 1794-1807 (1997). 
157. Giardina, G. A. et al. Discovery of a novel class of selective non-peptide antagonists for the human neurokinin-3 receptor. 2. Identification of (S)-N-(1-phenylpropyl)-3-hydroxy-2-phenylquinoline-4carboxamide (SB 223412). J. Med. Chem. 42, 1053-1065 (1999).

158. Sarau, H. M. et al. Nonpeptide tachykinin receptor antagonists: I. Pharmacological and pharmacokinetic characterization of SB 223412, a novel, potent and selective neurokinin-3 receptor antagonist. J. Pharmacol. Exp. Ther. 281, 1303-1311 (1997).

159. Sarau, H. M. et al. Nonpeptide tachykinin receptor antagonists. II. Pharmacological and pharmacokinetic profile of SB-222200, a central nervous system penetrant, potent and selective NK-3 receptor antagonist. J. Pharmacol. Exp. Ther. 295, 373-381 (2000).

160. Smith, P. W. et al. New quinoline NK3 receptor antagonists with CNS activity. Bioorg. Med. Chem. Lett. 19, 837-840 (2009).

161. Hay, D. W. et al. Nonpeptide tachykinin receptor antagonists. III. SB 235375, a low central nervous system-penetrant, potent and selective neurokinin-3 receptor antagonist, inhibits citric acid-induced cough and airways hyper-reactivity in guinea pigs. J. Pharmacol. Exp. Ther. 300, 314-323 (2002).

162. Li, Y. et al. In vitro assessment of metabolic drug-drug interaction potential of AZD2624, neurokinin3 receptor antagonist, through cytochrome $\mathrm{P}(450)$ enzyme identification, inhibition, and induction studies. Xenobiotica 40, 721-729 (2010).

163. Elliott, J. M. et al. N',2-diphenylquinoline-4-carbohydrazide based NK3 receptor antagonists II. Bioorg. Med. Chem. Lett. 16, 5752-5756 (2006).

164. Sarau, H. M. et al. Molecular and pharmacological characterization of the murine tachykinin NK(3) receptor. Eur. J. Pharmacol. 413, 143-150 (2001).

165. Griebel, G. \& Beeske, S. Is there still a future for neurokinin 3 receptor antagonists as potential drugs for the treatment of psychiatric diseases? Pharmacol. Ther. 133, 116-123 (2012).

166. Gordon, C. M. Clinical practice. Functional hypothalamic amenorrhea. N. Engl. J. Med. 363, 365$371(2010)$.

167. Blank, S. K., McCartney, C. R. \& Marshall, J. C. The origins and sequelae of abnormal neuroendocrine function in polycystic ovary syndrome. Hum. Reprod. Update 12, 351-361 (2006).

168. Seminara, S. B., Dipietro, M. J., Ramaswamy, S., Crowley, W. F.,Jr \& Plant, T. M. Continuous human metastin 45-54 infusion desensitizes $G$ protein-coupled receptor 54-induced gonadotropinreleasing hormone release monitored indirectly in the juvenile male Rhesus monkey (Macaca mulatta): a finding with therapeutic implications. Endocrinology 147, 2122-2126 (2006).

169. Ramaswamy, S. et al. Effect of continuous intravenous administration of human metastin 45-54 on the neuroendocrine activity of the hypothalamic-pituitary-testicular axis in the adult male rhesus monkey (Macaca mulatta). Endocrinology 148, 3364-3370 (2007).

170. Millar, R. P. in Reproductive medicine: molecular cellular and genetic fundamentals (ed Fauser, B. C. J. M.) (Parthenon Publishing, Lancaster, UK, 2002). 